\title{
Electrospinning Combined with Atomic Layer Deposition to Generate Applied Nanomaterials: A Review
}

\author{
Sesha Vempati,* Kugalur Shanmugam Ranjith, Fuat Topuz, Necmi Biyikli, and Tamer Uyar*
}

Cite This: ACS Appl. Nano Mater. 2020, 3, 6186-6209

\section{ACCESS | Llll Metrics \& More}

回国 Article Recommendations

ABSTRACT: Combining different material processing techniques is one of the keys to obtain materials that depict synergistic properties. In this review, we have reviewed a combination of two highly potential techniques, namely, electrospinning and atomic layer deposition (ALD), in the view of various applications. Over the past 10 years, our research groups are involved in the exploration of employing this combination for a range of applications. We also include some basic information on both the processes and diversity of nanostructures as a result of their combination. Nonwoven nanofiber membranes are excellent candidates for a wide range of applications. Also, they can act as templates to produce various other kinds of nanostructures when combined with ALD in small/large scale production. These nanostructures could be used as such or further subjected to other processing techniques yielding hierarchical structures. In this review, we exclusively survey and highlight the unique capabilities of combined electrospinning and ALD for applications in catalysis, photocatalysis, solar cells, batteries and gas sensors.

KEYWORDS: electrospinning, atomic layer deposition, hierarchical nanostructures, catalysis, batteries, sensors, ALD

\section{INTRODUCTION}

Material science crucially includes studies on the properties of various materials and their combinations. Notably, the properties of any material are dependent on the processing methodology. Also, enhancing and tailoring the functionality of an existing material is as important as that of discovering novel counterparts. The intrinsic properties of a material may depend on the physical dimensions, e.g., quantum confinement effect. There is a surge of various material processing techniques asserting some degree of control on the properties and physical dimensions; e.g., pulsed laser deposition, ${ }^{1}$ chemical vapor deposition, ${ }^{2}$ hydrothermal growth, ${ }^{3,4}$ electrospinning, ${ }^{5}$ atomic layer deposition (ALD),,$^{2,6-10}$ and so on. ${ }^{3,11,12}$ Now, in the context of enhancing and tailoring the functionality of a material, "combination(s)" of various material processing techniques are promising. The combination of electrospinning and ALD could address the needed high-surface area precisioncoated functional materials. Indeed, electrospinning is a versatile technique to produce nanofibers from polymers ${ }^{13}$ and nonpolymeric ${ }^{14}$ viscoelastic fluids yielding inorganic and ceramic materials. On the other hand, ALD is capable of producing conformal thin films as well as nanostructures (see Table 1). ${ }^{15,16}$ The materials spectra that can be deposited via ALD includes oxides, nitrides, sulfides, and metals among others. ${ }^{2,6-10}$ Individually, these techniques are rather successful to cover a wide range of applications including energy storage, ${ }^{17,18}$ solar cells, ${ }^{19,20}$ surface passivation, ${ }^{20,21}$ catalysis, $^{22-24}$ and flexible/wearable devices. ${ }^{25,26}$ Also, electrospun nanostructures find potential usage in (photo)catalysis, energy storage, $^{27}$ solar-cells, ${ }^{28,29}$ filtration, ${ }^{30}$ textile industry, ${ }^{31}$ wound dressing, $^{32}$ drug delivery, ${ }^{33}$ and environmental applications. ${ }^{34}$

The intersecting research areas of ALD and electrospinning capture significant attention due to the versatile applicability (Chart 1). By looking at the fundamental perspective of high surface area to volume ratio, structural integrity, surface electronic structure, and flexibility are some key requirements for high efficiency, either for catalysis, ${ }^{35}$ solar cells, ${ }^{36}$ batteries, ${ }^{37-44}$ heterogeneous catalysis, ${ }^{4,45,46}$ antimicrobial activity, $^{47}$ water purification, ${ }^{48,49}$ etc. For example, in the case of solar cells, higher current densities could be obtained for a relatively higher surface area of the device. ${ }^{29}$ In the case of catalytic reactions ${ }^{29,45} /$ gas sensors, ${ }^{50}$ a higher density of the active sites would be exposed to the reactants. It is found that the sensing performance of the core-shell nanostructures results from the radial modulation of the electron depletion

Received: April 26, 2020

Accepted: May 12, 2020

Published: May 12, 2020 
Table 1. Morphological Characterization of Nanostructures Produced with a Combination of Electrospinning and ALD

\begin{tabular}{|c|c|c|c|}
\hline SNo. & $\begin{array}{l}\text { Material/ } \\
\text { Nanostructure }\end{array}$ & Precursor & $\begin{array}{l}\text { Scanning and/or transmission electron micrographs of the } \\
\text { nanostructures }\end{array}$ \\
\hline 1 & $\begin{array}{l}\mathrm{TiO}_{2} \text { nanotubes of } \\
\sim 75 \mathrm{~nm} \text { wall } \\
\text { thickness } \\
\text { synthesized } \\
\text { through the thermal } \\
\text { decomposition } \\
\text { process }\end{array}$ & $\begin{array}{l}\text { Electrospinning: } \\
\text { PVAc, } \mathrm{H}_{2} \mathrm{O} \\
\text { ALD: TIP, } \\
\mathrm{H}_{2} \mathrm{O}, \mathrm{N}_{2} \text {-carrier gas }\end{array}$ & $\begin{array}{l}\text { Micrographs (left) TEM (right) SEM. Reproduced from ref }{ }^{64} \text {. Copyright } \\
2011 \text { John Wiley and Sons. }\end{array}$ \\
\hline 2 & $\begin{array}{l}\mathrm{ZrO}_{2} \\
\text { Core-shell fibers of } \\
\text { Poly(ether } \\
\text { sulfone)- } \mathrm{ZrO}_{2} \\
\text { nanofibers }\end{array}$ & $\begin{array}{l}\text { Electrospinning: } \\
\text { DMAc, PES } \\
\text { ALD: Tetrakis } \\
\text { (dimethylamido) } \\
\text { zirconium, } \mathrm{H}_{2} \mathrm{O}, \mathrm{N}_{2} \\
\text { as a carrier gas }\end{array}$ & TEM Micrograph ALD at $250{ }^{\circ} \mathrm{C}$. \\
\hline 3 & $\mathrm{HfO}_{2}$ core-shell & $\begin{array}{l}\text { Electrospinning: } \\
\text { Nylon } 6,6, \mathrm{HFIP} \text {, } \\
\text { formic acid } \\
\text { ALD: tetrakis } \\
\text { (dimethylamido) } \\
\text { hafnium, } \mathrm{H}_{2} \mathrm{O}, \mathrm{N}_{2-} \\
\text { carrier gas }\end{array}$ & $\begin{array}{l}\text { SEM image: } 600 \text { cycles } \mathrm{HfO}_{2} \text { deposited at } 200^{\circ} \mathrm{C} \text { on nanofibers of } 330 \mathrm{~nm} \\
\text { average diameter. } \\
\text { Reproduced from ref }{ }^{58} \text {. Copyright } 2013 \text { Elsevier. }\end{array}$ \\
\hline 4 & $\begin{array}{l}\mathrm{HfO}_{2} \text { hollow } \\
\text { nanofibers }\end{array}$ & $\begin{array}{l}\text { Electrospinning: } \\
\text { Nylon } 6,6 \text {; HFIP, } \\
\text { formic acid } \\
\text { ALD: Tetrakis } \\
\text { (dimethylamido) } \\
\text { hafnium, } \mathrm{H}_{2} \mathrm{O}, \mathrm{N}_{2} \\
\text { carrier gas }\end{array}$ & $\begin{array}{l}\text { (e) } \\
\text { SEM image: } \mathrm{HfO}_{2} \text { hollow nanofibers, deposited at } 200{ }^{\circ} \mathrm{C} \text { with } 600 \text { cycles. } \\
\text { TEM Image: } \mathrm{Micrograph}_{\mathrm{H}} \mathrm{HfO}_{2} \text { hollow nanofiber. Reproduced from ref } \\
{ }^{5} \text {. Copyright } 2013 \text { Elsevier. }\end{array}$ \\
\hline
\end{tabular}


Table 1. continued

\begin{tabular}{|c|c|c|c|}
\hline SNo. & $\begin{array}{l}\text { Material/ } \\
\text { Nanostructure }\end{array}$ & Precursor & $\begin{array}{l}\text { Scanning and/or transmission electron micrographs of the } \\
\text { nanostructures }\end{array}$ \\
\hline 5 & $\begin{array}{l}\text { AlN/BN } \\
\text { bi-shell hollow } \\
\text { nanofibers }\end{array}$ & $\begin{array}{l}\text { Electrospinning: } \\
\text { nylon } 6,6 \text {, formic } \\
\text { acid } \\
\text { ALD: } \\
\text { trimethylaluminum, } \\
\mathrm{N}_{2} / \mathrm{H}_{2} \text { plasma, Ar- } \\
\text { carrier gas }\end{array}$ & $\begin{array}{l}\text { (left) SEM (right) Bright field } \mathrm{TEM} \text { image hollow nanofiber having an } \\
\text { average inner fiber diameter of } \sim 100 \text { nm with an average wall thickness of } \\
\sim 20 \text { nm and } \sim 35 \text { nm of AlN and BN, respectively. Reproduced from ref }{ }^{55} \text {. } \\
\text { Licensed under a Creative Commons Attribution (CC BY) license, } \\
\text { American Institute of Physics. }\end{array}$ \\
\hline 6 & $\begin{array}{l}\mathrm{ZnO} / \mathrm{ZnAl}_{2} \mathrm{O}_{4} \\
\text { multilayered } \\
\text { nanotubes: } \\
\text { Multilayered } \\
\text { deposition with } \\
\text { varying the number } \\
\text { of cycles, } 60^{\circ} \mathrm{C} \text {. } \\
\text { Nanotubes are } \\
\text { obtained after } \\
\text { calcining at } 450{ }^{\circ} \mathrm{C} \text {. }\end{array}$ & $\begin{array}{l}\text { Electrospinning: } \\
\text { PAN, DMF } \\
\text { ALD: DEZn, TMA. }\end{array}$ & $\begin{array}{l}\text { Triple } \\
\text { SEM image: } \mathrm{ZnO} / \mathrm{ZnAl}_{2} \mathrm{O}_{4} \text { triple and quadruple co-centric nanotubes } \\
\text { annealed in air at } 900{ }^{\circ} \mathrm{C} \text {. } \\
\text { Reproduced from } \mathrm{ref}^{108} \text {. Copyright } 2016 \text { Royal Society of Chemistry. }\end{array}$ \\
\hline 7 & $\begin{array}{l}\mathrm{ZnO} \text { nanoparticles } \\
\text { (NPs) }\end{array}$ & $\begin{array}{l}\text { Electrospinning: } \\
\text { Nylon } 6,6 \text {, formic } \\
\text { acid } \\
\text { ALD: } \\
\text { DEZn, } \mathrm{H}_{2} \mathrm{O}, \mathrm{N}_{2^{-}} \\
\text {carrier gas }\end{array}$ & $\begin{array}{l}\text { SEM images (left) nylon-ZnO NPs, (middle) TEM images nylon-ZnO } \\
\mathrm{NPs} \text {, (right) nylon-ZnO NPs (highly dense). Reproduced from ref } \\
{ }^{109} \text {. Copyright 2013 Royal Society of Chemistry. }\end{array}$ \\
\hline 8 & $\begin{array}{l}\text { Nylon-GaN core- } \\
\text { shell nanofiber } \\
\text { produced through } \\
\text { hollow cathode } \\
\text { plasma assisted } \\
\text { ALD at } 200^{\circ} \mathrm{C} \text {. }\end{array}$ & $\begin{array}{l}\text { Electrospinning: } \\
\text { Nylon } 6,6 \text {, formic } \\
\text { acid } \\
\text { ALD: } \mathrm{TMG}, 5 \mathrm{~N}- \\
\text { grade } \mathrm{N}_{2}, \mathrm{H}_{2}, \mathrm{Ar}\end{array}$ & (b) \\
\hline
\end{tabular}


Table 1. continued

\begin{tabular}{|c|c|c|c|}
\hline SNo. & $\begin{array}{l}\text { Material/ } \\
\text { Nanostructure }\end{array}$ & Precursor & $\begin{array}{l}\text { Scanning and/or transmission electron micrographs of the } \\
\text { nanostructures }\end{array}$ \\
\hline 9 & $\begin{array}{l}\mathrm{BiVO}_{4}-\mathrm{ZnO} \\
\text { microbelts }\end{array}$ & $\begin{array}{l}\text { Electrospinning: } \\
\text { PVP, } \\
\mathrm{Bi}\left(\mathrm{NO}_{3}\right)_{3} \cdot 5 \mathrm{H}_{2} \mathrm{O} \text { and } \\
\mathrm{VO}(\mathrm{acac})_{2}, \\
\text { diisopropylamine } \\
\mathrm{ALD} \text { : DEZn, } \mathrm{H}_{2} \mathrm{O} \text {, } \\
\mathrm{N}_{2} \text {-carrier gas }\end{array}$ & $\begin{array}{l}\text { (c) } \rightarrow \text { Manoclinic BiVO, (i) } \\
\text { TEM images: (top row) } \mathrm{BiVO}_{4} @ \mathrm{ZnO} \text { microbelts for } 400 \text { cycles of } \\
\text { the single microbelt recorded from marked area A in the top row and a } \\
\text { HRTEM image recorded from the marked area B in the top row. } \\
\text { Reproduced from ref }{ }^{110} \text {. Copyright } 2018 \text { Elsevier. }\end{array}$ \\
\hline 10 & $\begin{array}{l}\mathrm{ZnO} / \mathrm{TiO}_{2} \text { and } \\
\mathrm{TiO}_{2} / \mathrm{ZnO} \\
\text { core-shell } \\
\text { nanofibers }\end{array}$ & $\begin{array}{l}\text { Electrospinning: } \\
\text { PVP, TIP, ZnAc } \\
\text { DMF, EtOH, glacial } \\
\text { acetic acid. } \\
\text { ALD: TDMAT, } \\
\text { DEZn, and HPLC } \\
\text { grade } \mathrm{H}_{2} \mathrm{O}\end{array}$ & $\begin{array}{l}\text { TEM images: Core-shell heterojunction nanofibers (left) } \mathrm{ZnO}-\mathrm{TiO}_{2} \text {, (right) } \\
\mathrm{TiO}_{2} \text {-ZnO. Reproduced from ref }{ }^{46} \text {. Copyright } 2014 \text { Royal Society of } \\
\mathrm{Chemistry}^{2}\end{array}$ \\
\hline 11 & $\begin{array}{l}\mathrm{SnO}_{2} \\
\text { microtube yarns } \\
\text { obtained by } \\
\text { twisting the } \\
\text { sacrificial PAN } \\
\text { nanofibers and } \\
\text { deposit } \mathrm{SnO}_{2}\end{array}$ & $\begin{array}{l}\text { Electrospinning: } \\
\text { PAN, DMF } \\
\text { ALD: } \\
\text { Dibutyltindiacetate }\end{array}$ & $\begin{array}{l}\text { (b) } \\
\mathrm{SEM} \text { images: (left) } \mathrm{SnO}_{2} \text { coated yarn by } \mathrm{ALD} \text { and (right) } \mathrm{SnO}_{2} \text { nanotube } \\
\text { yarn after calcination. Reproduced from ref }{ }^{111} \text {. Copyright } 2011 \mathrm{IOP} \\
\text { Publishing. }\end{array}$ \\
\hline
\end{tabular}


Table 1. continued

\begin{tabular}{|c|c|c|c|}
\hline SNo. & $\begin{array}{l}\text { Material/ } \\
\text { Nanostructure }\end{array}$ & Precursor & $\begin{array}{l}\text { Scanning and/or transmission electron micrographs of the } \\
\text { nanostructures }\end{array}$ \\
\hline 12 & $\begin{array}{l}\mathrm{TiO}_{2} / \mathrm{ZnO} \text { double } \\
\text { layered hollow } \\
\text { nanofibers } \\
\text { ALD of two } \\
\text { different inorganic } \\
\text { materials }\end{array}$ & $\begin{array}{l}\text { Electrospinning: } \\
\text { PVAc, EtOH } \\
\text { ALD: TIP, DEZn, } \\
\mathrm{H}_{2} \mathrm{O}\end{array}$ & $\begin{array}{l}\text { SEM image: (left) } \mathrm{TiO}_{2} / \mathrm{ZnO} \text { double layer hollow for } 350 \text { cycles. } \\
\text { TEM image: (right) } \mathrm{TiO}_{2} / \mathrm{ZnO} \text { double layer hollow fiber with } 8 \mathrm{~nm} \text { thick } \\
\mathrm{ZnO} \text { outer layer. Reproduced from ref }{ }^{57} \text {. Copyright } 2014 \text { American } \\
\text { Chemical Society. }\end{array}$ \\
\hline 13 & $\begin{array}{l}\mathrm{CuO} \mathrm{ZnO} \text { core- } \\
\text { shell structure }\end{array}$ & $\begin{array}{l}\text { Electrospinning: } \\
\text { PVA, copper } \\
\text { acetate, } \mathrm{H}_{2} \mathrm{O} \\
\text { ALD: DEZn, } \mathrm{H}_{2} \mathrm{O} \\
\mathrm{N}_{2} \text {-carrier gas }\end{array}$ & $\begin{array}{l}\text { (త) } \\
\text { TEM image: (left) Low-magnification } \mathrm{TEM} \text { image of an individual p- } \\
\mathrm{CuO} / \mathrm{n}-\mathrm{ZnO} \text { core-shell nanofiber with a } 16-\mathrm{nm} \text {-thick shell layer. What } \\
\text { follows are EDS elemental maps are shown for } \mathrm{O}, \mathrm{Cu} \text { and } \mathrm{Zn} \text {. Reproduced } \\
\text { from ref }{ }^{112} \text {. Copyright } 2014 \text { IOP Publishing. }\end{array}$ \\
\hline 14 & $\begin{array}{l}\text { Core-shell } \\
\mathrm{WO}_{3} / \mathrm{TiO}_{2} \\
\text { Treated at } 550{ }^{\circ} \mathrm{C} \\
\text { to yield } \mathrm{WO}_{3} \\
\text { nanofibers. }\end{array}$ & $\begin{array}{l}\text { Electrospinning: } \\
\text { ammonium } \\
\text { metatungstate, PVP. } \\
\text { ALD: } \mathrm{TiCl}_{4}, \mathrm{H}_{2} \mathrm{O} \\
\mathrm{N}_{2} \text {-carrier gas }\end{array}$ & 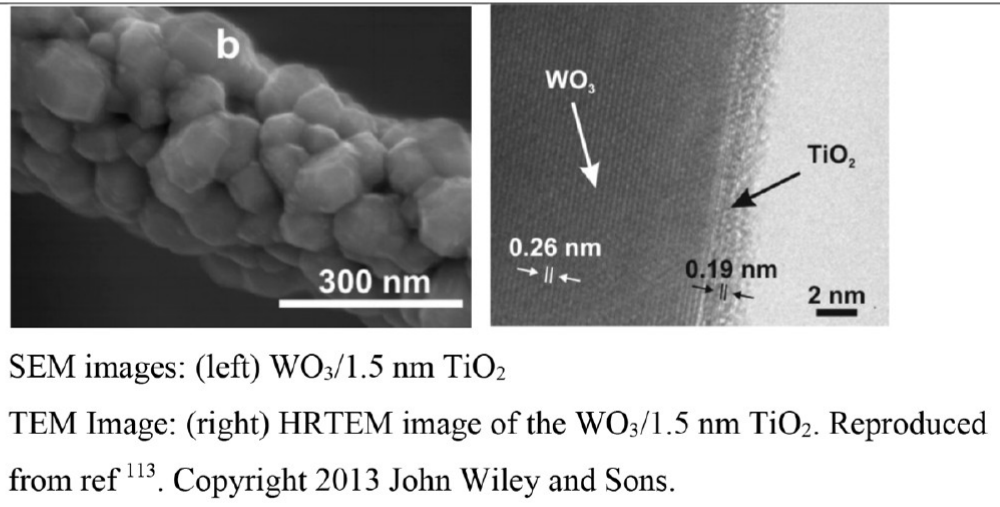 \\
\hline 15 & $\begin{array}{l}\mathrm{TiO}_{2}-\mathrm{SnO}_{2}-\mathrm{TiO}_{2} \\
\text { trilayered tubular } \\
\text { nanostructures }\end{array}$ & $\begin{array}{l}\text { Electrospinning: } \\
\text { PAN, DMF } \\
\text { ALD: Dibutyltin } \\
\text { diacetate, TIP }\end{array}$ & \begin{tabular}{l|l|l|l|}
$\mathbf{c}$ \\
TEM image: (left) shows the trilayered tubular structure, (right) shows \\
EDS mapping of a selected region shown Ti, Sn and O. Reproduced from \\
ref ${ }^{114}$. Copyright 2017 Springer.
\end{tabular} \\
\hline
\end{tabular}


Table 1. continued

\begin{tabular}{|c|c|c|c|}
\hline SNo. & $\begin{array}{l}\text { Material/ } \\
\text { Nanostructure }\end{array}$ & Precursor & $\begin{array}{l}\text { Scanning and/or transmission electron micrographs of the } \\
\text { nanostructures }\end{array}$ \\
\hline 16 & $\begin{array}{l}\text { Germanium@ } \\
\text { graphene@ } \mathrm{TiO}_{2} \\
\text { core-shell }\end{array}$ & $\begin{array}{l}\text { Electrospinning: } \\
\text { PVP, graphene in } \\
2.2 \text { g of DMF, } \\
\mathrm{GeCl}_{4} \text {. } \\
\mathrm{ALD} \text { : TIP, } \mathrm{H}_{2} \mathrm{O}, \mathrm{N}_{2-} \\
\text { carrier gas }\end{array}$ & $\begin{array}{l}\text { b } \\
\text { TEM images: (left) Ge@G@, } \mathrm{TiO}_{2} \text { (right) HRTEM of Ge showing } \\
\text { nanocrystalline Ge grains in a highly ordered matrix. Reproduced from ref } \\
\text { 39. Copyright 2016 John Wiley and Sons. }\end{array}$ \\
\hline 17 & $\begin{array}{l}\mathrm{ZnO} \text { nano needles } \\
\text { core-shell structure }\end{array}$ & $\begin{array}{l}\text { Electrospinning: } \\
\text { PAN, DMF, ALD: } \\
\text { DEZn, } \mathrm{H}_{2} \mathrm{O}, \mathrm{N}_{2^{-}} \\
\text {carrier gas }\end{array}$ & 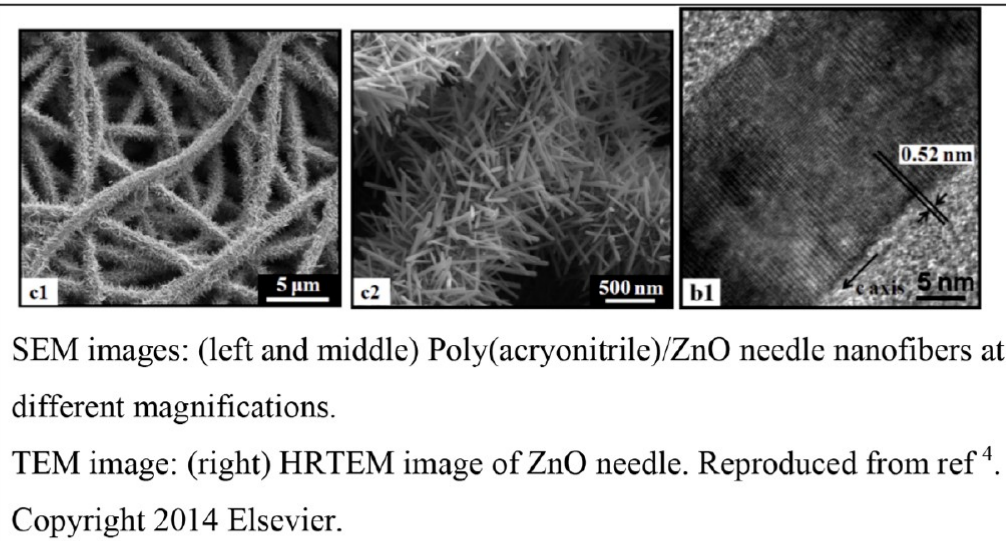 \\
\hline 18 & $\begin{array}{l}\Omega \text { shaped } \mathrm{ZnO} \\
\text { coated } \mathrm{SnO}_{2} \\
\text { nanofibers }\end{array}$ & $\begin{array}{l}\text { Electrospinning: } \\
\mathrm{SnCl}_{2} \cdot 2 \mathrm{H}_{2} \mathrm{O}, \mathrm{EtOH} \text {, } \\
\mathrm{PVP}, \mathrm{DMF} \\
\text { ALD: DEZn, } \mathrm{H}_{2} \mathrm{O} \text {, } \\
\mathrm{N}_{2} \text {-carrier gas }\end{array}$ & $\begin{array}{l}\text { SEM image: (left) Side view of } \mathrm{SnO}_{2} \text { nanofiber and (right) } \mathrm{SnO}_{2} @ \mathrm{ZnO} \\
\text { showing the } \Omega \text { shape. Scale bars are } 200 \mathrm{~nm} \text { in (left), and } 100 \mathrm{~nm} \text { in } \\
\text { (right). Reproduced from ref }{ }^{53} \text {. Copyright } 2017 \mathrm{John} \text { Wiley and Sons. }\end{array}$ \\
\hline
\end{tabular}

region as a function of the thickness of the shell. ${ }^{51}$ Furthermore, due to the band alignment, the hybrid semiconducting structures, in general, possess an internal electric field. They also depict the tunability of electronic and optical properties. $^{52}$ This built-in electric field could separate the photogenerated charge carriers before recombination, which has significant potential in solar cells, photodetectors, and photocatalysis. ${ }^{46}$ These heterostructures facilitate trapping of photons and wavelength selectivity could also be achieved when the photons are suitably confined. ${ }^{53}$ The combination produces core-shell, ${ }^{54}$ bishell hollow, ${ }^{55-57}$ hollow nanofibers, $^{45,58-62}$ and metal nanoparticle-loaded ${ }^{47,63-65}$ nanofibrous templates (see Chart 1). This combination can be extended to form advanced multilevel structures, such as $\mathrm{Al}_{2} \mathrm{O}_{3} / \mathrm{Ni} / \mathrm{Al}_{2} \mathrm{O}_{3},{ }^{66} \mathrm{SrTiO}_{3} / \mathrm{SrTiO}_{3},{ }^{67}$ polymer $/ \mathrm{TiO}_{2} / \mathrm{Pt}$ nanoparticles, ${ }^{68}$ etc. Furthermore, inorganic material coated polymer fibers could be subjected to hydrothermal, ${ }^{4}$ chemical bath, ${ }^{69}$ and microwave-assisted solvothermal ${ }^{70}$-like methods. For instance, hydrothermal growth ${ }^{4}$ yields nanorods of high crystalline quality, which provides highly efficient channels for the transport of both electrons and holes to the surface, while the solvothermal technique ${ }^{70}$ can produce metal-organic frameworks.

As discussed earlier, the application potential of these techniques is reflected in a significant number of publications and patents on catalysis, batteries, and sensor applications (Figure 1). Keeping this in mind, this review covers the literature strictly focusing on the combination of electrospinning and ALD. Figure 1a shows the year-wise number of publications, while Figure $1 \mathrm{~b}$ shows three major corresponding research topics. By given the industrial applicability of these topics, we have also plotted the year-wise number of patents in 
Chart 1. Salient Features of Electrospinning, Atomic Layer Deposition and Their Combination Are Shown ${ }^{a}$

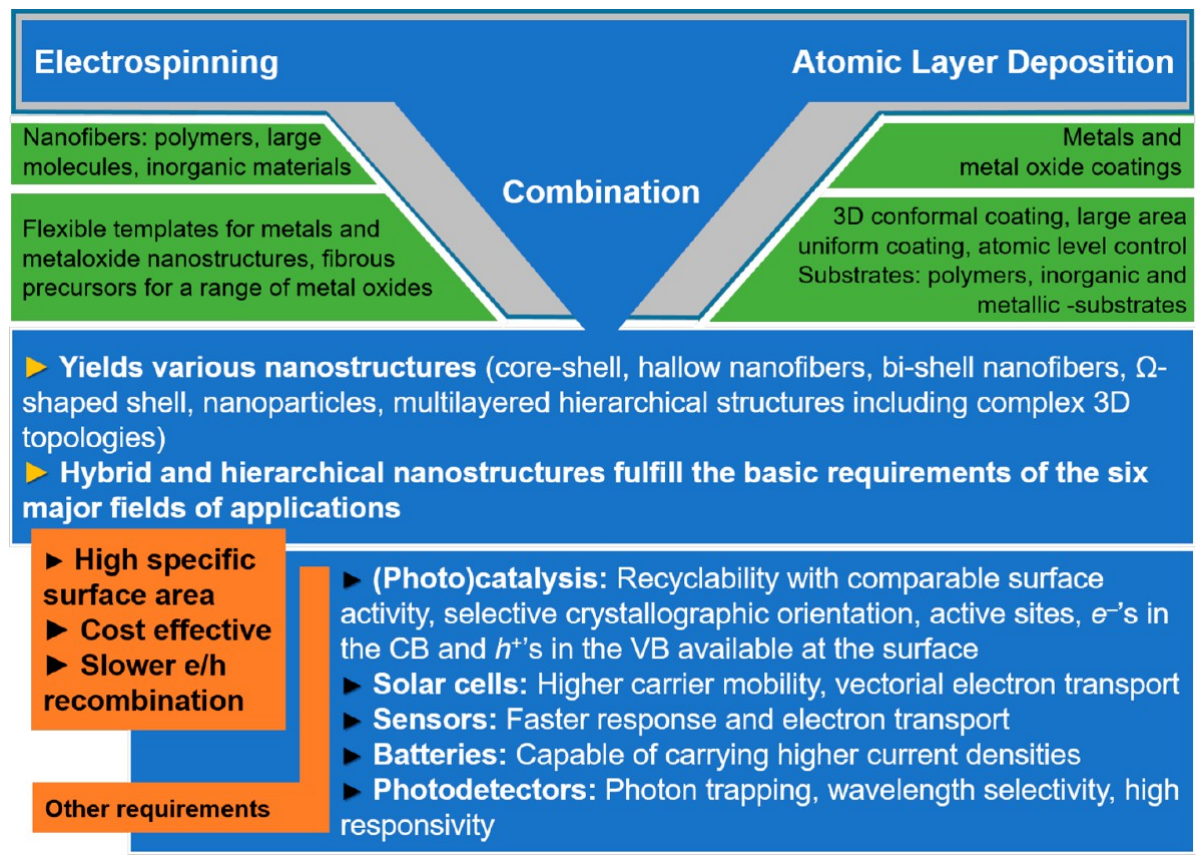

${ }^{a}$ It also shows a broad range of hierarchical nanostructures as a result of this combination. The chart also highlights the applicability of these nanostructures that covers the basic requirements of each of the major field of application.
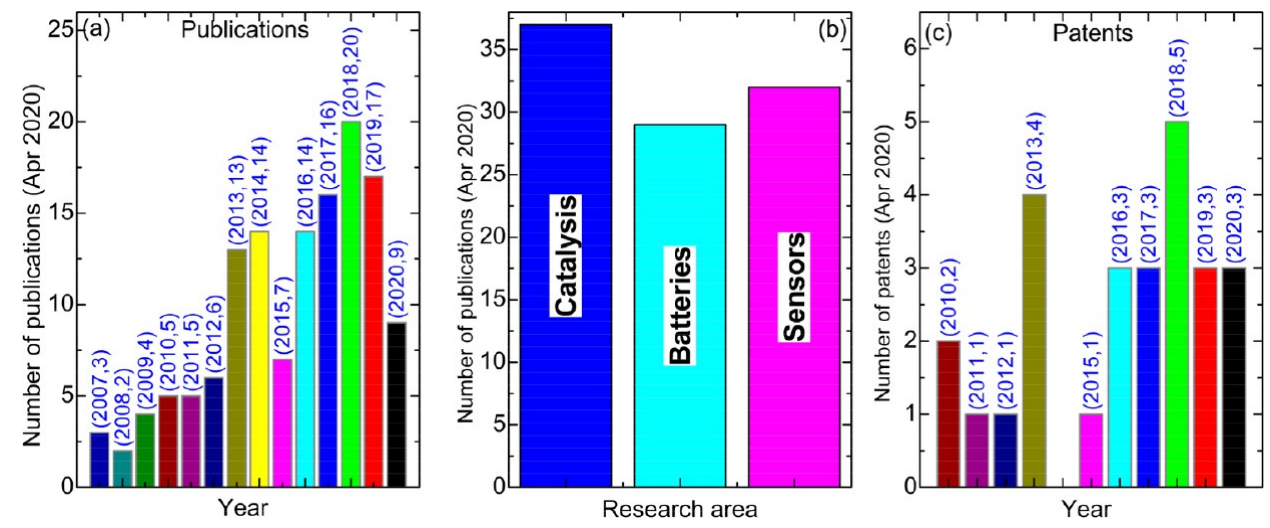

Figure 1. Year-wise statistical analyses on the research topic "electrospinning + atomic layer deposition" (a) number of publications, (b) major research areas, and (c) number of patents. Data updated as of April 24, 2020.

Figure 1c. We start the review by briefly discussing the processes of electrospinning and ALD.

Electrospinning. A charged polymer jet is accelerated (within an electric field of $10^{5}-10^{6} \mathrm{~V} / \mathrm{m}$ ) toward the counter electrode from a fine nozzle forming a Taylor cone. ${ }^{13}$ The electrostatic repulsion between surface charges induces "splaying" of the cone into several fine strands and continuously drawn nanofibers onto the substrate (counter electrode). The substrate can be, for example a rotating drum, which yields aligned nanofibers when the spinning and collection rates are balanced. ${ }^{71} \mathrm{~A}$ cartoon of the electrospinning process and various types of collecting electrodes are shown in Figure 2. The schematic also shows core-shell, triaxial, and multineedle spinnerets. Such spinnerets, together with the formulation parameters, enable the production of fibers with different morphologies, such as hollow, flat/ribbon, core-shell, porous, and Janus. The electrospinning process has been applied to produce microns to sub-100 nm sized fibers from a rich variety of materials, like polymers, ceramics, nonpolymeric materials, ${ }^{72}$ nanocomposites, ${ }^{73}$ etc. up to the industrial-scale. ${ }^{74-77}$ Electrospinning also finds vast applicability in tissue engineering, ${ }^{78}$ water-treatment, ${ }^{79}$ and the food packing industry. ${ }^{80}$ It has also been adapted to produce a number of other nanostructures, such as microchannels and tubes, $^{81}$ porous, ${ }^{82}$ hollow, or core-shell structures (e.g., biphasic nanofibers with a conducting core with an insulating shell $^{83}$ ). It is also possible that the polymers that are intrinsically microporous can be subjected to electrospinning to obtain a relatively higher surface area to volume ratio when compared to that of the nonporous counterparts. ${ }^{82}$ The polymer of intrinsic microporosity has a high fractional freevolume $(26 \%)$ and is reported to have a BET surface area of $760 \mathrm{~m}^{2} / \mathrm{g}^{84}$

Up-Scaling of Electrospinning. Apart from optimization of the basic electrospinning parameters, up-scaling of the process usually employs multispinnerets and a suitable power supply. Also certain changes to the collecting electrodes need to be implemented depending on the application. Since the 


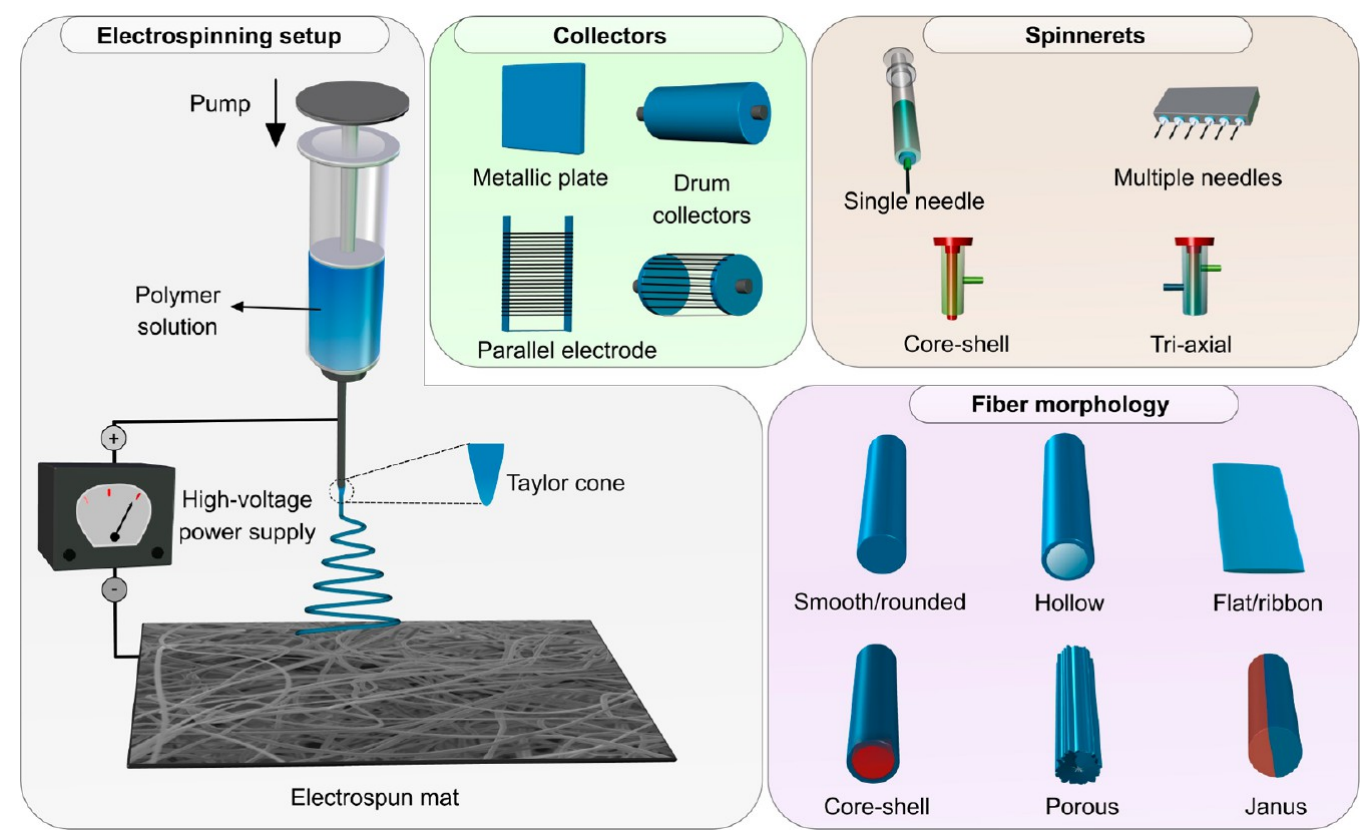

Figure 2. Schematic of the electrospinning process. Schematic also shows typical collectors and spinnerets. Reproduced from ref 80 . Copyright 2020 Elsevier.

nanofibers are subjected to ALD, it is important to collect the nanofibers such that the additional precursor diffusion step is feasible. In fact, various companies supply the laboratory and industrial-scale components for electrospinning for different applications. They include Spingenix, Inovenso, Bioinicia, Elmarco, Yflow, IME, RevolutionFibres, Nanofiber Solutions, Spraybase, Mecc Co., Ltd., and so on. Electrospinning has been successfully exploited in industry. The industrial aspect of electrospun nanofibers is directly visible, where a number of companies around the globe (Europe, ${ }^{85-93}$ USA, $^{94-96}$ Asia, ${ }^{97,98}$ Japan, ${ }^{99}$ South Africa, ${ }^{100}$ New Zealand, ${ }^{101}$ ) produce nanofibers for various applications. Some of these companies not only design but also manufacture electrospun nanofibrous materials for filter media, biomedical applications, wound dressing, drug delivery systems, textiles, cosmetics and hygiene products, etc. Readers are advised to refer to a review by Persano et al. ${ }^{74}$ and other references ${ }^{74-77}$ for further details on the industrial up-scaling of electrospinning. For large scale production of electrospun nanofibers, multinozzle ${ }^{102}$ or nozzleless $^{92,100}$ electrospinning could be employed. The electrospinning yield can be enhanced using alternating current, which relies on an electrostatic field with periodically changing polarity. Alternating current electrospinning yields multiple times higher productivities achieved with direct current electrospinning. ${ }^{103}$

Advantages. The major advantages of the electrospinning process can be listed as the following. (1) This technique is relatively simple, (2) cost-effective (a few thousand dollars) to implement, (3) nanofibers of high surface area to volume ratio from a wide variety of polymers and precursors of ceramic, inorganic, and metals, (4) any modification/functionalization is relatively easy, (5) it allows one to produce nanofibers of composites, (6) nanofibers can be collected onto many different surfaces such as glass, metals, water, etc., (7) various nanofibrous structures can be synthesized using hierarchical methods, (8) polymer chain ordering or macromolecular crystallinity increases, and (9) feasibility of industrial level high-volume mass-production.
Disadvantages. There are some disadvantages of the electrospinning process. (1) This technique requires viscoelectic precursor, (2) conductivity should be at a moderate level for easy electrospinning, (3) obtaining single crystalline and continuous inorganic fibers are rather difficult, (4) needs the usage of solvents which may be toxic, (5) insufficient cell infiltration and inhomogeneous cell distribution in tissue engineering applications, (6) no/very-limited control on 3D porosity, (7) diameter of the nanofiber cannot be controlled with high precision, and (8) bead formation may be inevitable as the diameter of the fiber decreases, where beads reduce the surface area to volume ratio.

Hardware and Cost of Ownership. Electrospinning is one of the very economical techniques to produce nanofibers. As shown in Figure 2, the setup requires a syringe pump, collection screen, and a high voltage power-supply. Depending on the number of spinning needles (Figure 2), an appropriate power supply needs to be employed so that sufficient current is supplied. Additionally, the whole setup can be installed in an enclosure. This enables continuous spinning where the influence of propellant air is reduced. A lab-scale, commercial setup costs some 1000 USD including a user control on the various features, such as speed of rotating mandrel, duration of the spinning, flow rate in the syringe pump, heating the spinning environment up to $45^{\circ} \mathrm{C}$, and so on. To produce inorganic nanofibers, an oven is required which costs around 1500 USD. Similar to other fiber production techniques, the precursor polymeric materials and relevant solvents are not very expensive. The applicability of this technique to various polymers is one of the most important aspects. When the polymeric nanofibers are used as templates, then a relatively wide distribution of molecular weight of the polymer would still work, reducing the total cost. However, additional cost incurs from the precursor for inorganic nanofibers. Perhaps, during industrial scale production, the evaporated solvent could be recovered through condensing the vapors. This not only makes the whole process cost-effective but also environmentally friendly. 
Atomic Layer Deposition. ALD is a low-temperature chemical vapor deposition technique where the material growth is governed by sequential self-saturating gas-solid surface reactions. ${ }^{7-10}$ Conventional gas-phase reactions and thermal decomposition of precursor molecules are eliminated by temporally or spatially separated half-cycles, which leads to digital/pulsed film deposition that proceeds with self-limiting ligand-exchange surface reactions only. 8,9

The typical unit deposition cycle of a conventional ABABtype ALD process consists of four steps: (i) dosing of the metal-containing precursor, which reacts with the active surface groups via chemisorption until surface saturation is achieved, (ii) purging step with an inert gas flow, which will completely remove the excess precursor molecules as well as the ligand-exchange reaction byproducts, (iii) dosing of the second precursor, which is in general defined as the coreactant, which likewise reacts with the chemisorbed surface groups via ligand exchange reactions until saturation, (iv) second purging cycle to evacuate the reactor chamber from excess amounts of precursors and reaction byproducts.

As precursor molecules do not react with themselves and both precursors react only with the chemisorbed groups on the substrate surface, gas-phase chemical vapor deposition-type reactions are entirely eliminated. Each unit cycle results in a material deposition of a certain film thickness, which is mostly a fraction of a monolayer, and is defined as the growth-percycle value. ${ }^{8}$ Under ideal self-limiting conditions, the characteristic growth-per-cycle value would remain constant within a certain temperature range (ALD window) where no thermal decomposition takes place. For certain materials, the conventional thermal ALD process at substrate temperatures lower than precursor decomposition does not result in any film deposition. In such cases, plasma-assisted deposition might help in lowering the deposition temperature with the help of energetic coreactant radical species. ${ }^{104}$ The main drawback or risk with plasma-ALD is the possible plasma damage, which might be particularly significant for polymeric electrospun nanofibers. Figure 3 shows a unit plasma-ALD process cycle for AlN, with the precursor (trimethylaluminum-TMA) and plasma coreactant $\left(\mathrm{N}_{2} / \mathrm{H}_{2} / \mathrm{Ar}\right)$ exposure events separated by $\mathrm{N}_{2}$ /Ar-purge cycles and how these process steps affect the reactor pressure during the growth experiment. ${ }^{105}$

Up-Scaling. For the up-scaling of ALD toward industrialscale high-volume production, deposition rates need to be increased while not sacrificing from the ideal uniformity and conformality. The growth-per-cycle (GPC) parameter in ALD processes is pretty fixed and range typically within $0.5-2.0 \AA$; however, the total time needed to complete the unit ALD cycle might be further reduced with reactor and precursor pulsing designs. Particularly, "spatial ALD" features dramatically increased the deposition rates where the substrate is physically moved in the spatial domain rather than waiting for purging the active species out of the chamber in the time domain. Using spatial ALD, orders of magnitude higher growth rates have been achieved for several materials. Spatial ALD, therefore, can in principle be applied for the ALD coating of electrospun nanofiber templates as well as where the additional precursor diffusion step needs to be incorporated. Furthermore, as the polymeric nanofibrous templates can be woven on flexible substrates, even roll-to-roll ALD processes might be feasible to develop which might further reduce the unit production cost of such ALD-coated nanofiber materials.

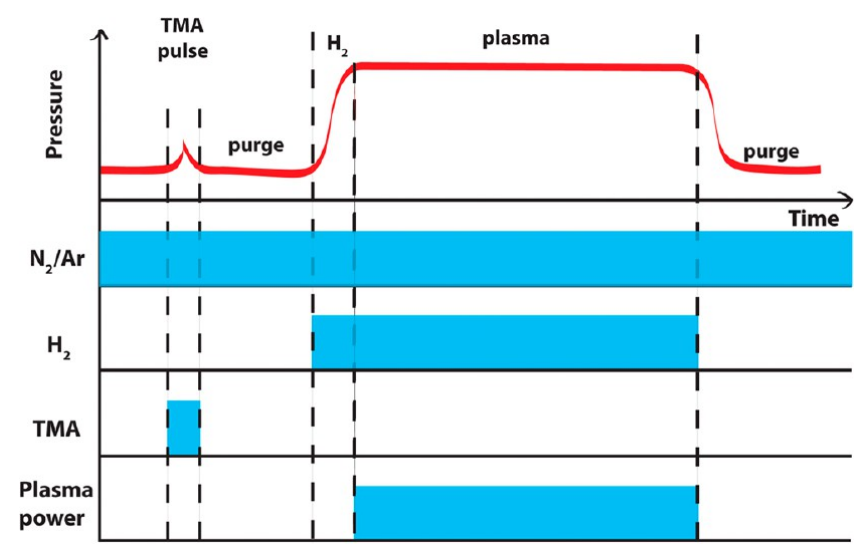

Figure 3. Temporal process layout for a unit plasma-ALD cycle of AlN and the corresponding variation of the reactor pressure over time. Initially, TMA pulse is introduced into the chamber onto the substrate, which is then adsorbed forming a monolayer. The excess precursor is pumped out. Then reactive $\mathrm{N}_{2} / \mathrm{H}_{2}$ plasma species are introduced to the surface which react with the adsorbed TMA to form AlN via ligand-exchange surface reactions. Then unreacted $\mathrm{N}_{2} / \mathrm{H}_{2}$ plasma radicals are purged out of the system to prevent subsequent gas-phase reactions. Reproduced from ref 105. Copyright 2019 American Vacuum Society.

Advantages. (1) Thermal ALD yields a very good conformality over large surface areas, (2) scalable up to industrial levels for high-volume production, (3) wide range of inorganic materials toward various application interests can be produced, and (4) novel precursors can be designed and synthesized which might be used for alternative surfaces, materials, and applications.

Disadvantages. (1) Possible chemical reactions between the polymer nanofibers and the ALD-precursor may limit the applicability. As a result, the interface may not be well-defined. (2) Due to the directionality of the plasma-ALD, it requires protective coating on the polymeric template. The plasmaassisted ALD may not yield a uniform coating on the high surface area nanofibrous templates. (3) ALD is limited by the availability of the gaseous precursors with sufficient vapor pressure and high thermal stability.

Hardware and Cost of Ownership. Practically any welldesigned ALD reactor, either thermal or plasma-assisted ALD systems are sufficient to provide uniform and conformal coatings on nanofibers or nanoparticle templates. The main requirement is the ALD recipe which will allow the precursor and coreactant molecules to diffuse freely within the nanotemplate. To achieve this condition, conventional thinfilm coating ALD recipes are further modified with extra "waiting periods" after the precursor/coreactant molecules are pulsed into the reactor chamber. Typically, for flat substrate coating experiments, the precursor/coreactant pulsing is followed by an immediate $\mathrm{N}_{2} /$ Ar purging step, without any need for an additional waiting period. For nanofiber/ nanoparticle template coating experiments, depending on the effective surface area of the template, additional diffusion periods of $30-180 \mathrm{~s}$ are utilized to ensure complete coverage of all available surfaces. On a side note, although we mentioned that plasma-ALD can provide conformal coatings as well, it is also known that plasma processes exhibit inherent directionality due to the directional flow of energetic radicals and ions, which might result in reduced conformal coating performance. In our work, ${ }^{54,55}$ we have demonstrated AlN and GaN coated 
(a)

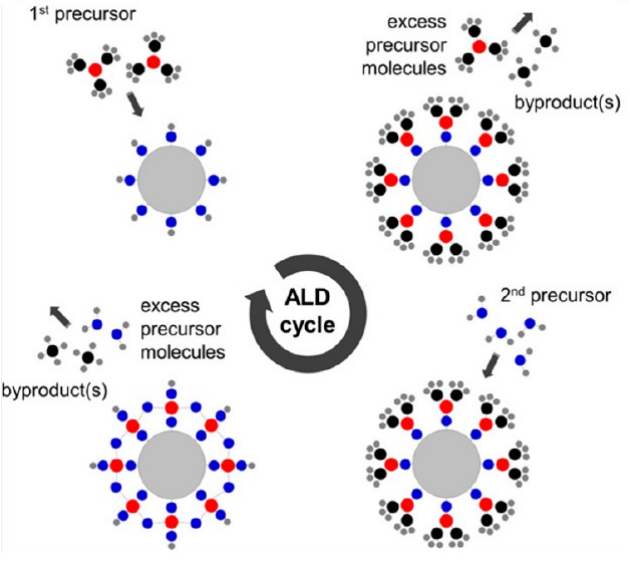

(b)

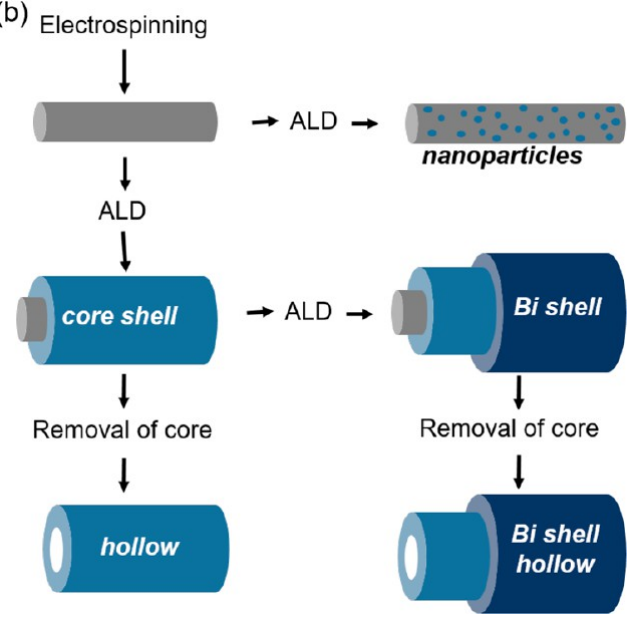

Figure 4. (a) Schematic representation of a unit ALD cycle and (b) electrospun nanofiber-based synthesis of nanostructures. Inorganic nanoparticle coated core-shell, bishell, hollow, and bishell hollow nanofibers. To prepare these nanostructures, we start with a nanofiber template and a conformal deposition of required material takes place on top of the template. By selectively removing the organic template by calcination, the above listed nanostructures could be obtained. Part a is reproduced from ref 106 Copyright 2013 John Wiley and Sons.

nanofibers via plasma-assisted ALD with decent (but not perfect) conformality. Our thermal-ALD coated nanofibers exhibited much improved conformality, as no directional coreactants are present in thermal-ALD experiments. Nevertheless, plasma-ALD recipes can be tuned and adjusted to show enhanced conformality, mainly by optimizing the reactor pressure and the related radical residency times within the reactor chamber.

Cost of commercial ALD reactors are typically of less or equal (if heavily equipped with in situ metrology tools) value when compared to widely used PVD systems like sputtering and of significant lower cost when compared to epitaxial growth reactors including MOCVD and MBE. On the other hand, precursor materials are the main consumables for ALD coatings, which are typically expensive if purchased from a few available precursor vendors. This cost item can be reduced if such precursor materials can be synthesized in-house. However, for most of the applications including (photo)catalysis, energy storage, gas sensing, passivation, and transistor fabrication, typically less-than $20 \mathrm{~nm}$ and in some cases just a few monolayer-thick coatings are needed, which makes ALD the only viable option with still relatively low operation cost. In this case, the ownership cost including the consumables further reduces as the expensive precursor can be used for the coating of a high number of samples.

\section{ELECTROSPINNING AND ATOMIC LAYER DEPOSITION}

The integration of electrospinning and ALD are schematized in Figure 4. Figure 4a shows the schematic of a typical unit ALD cycle with precursor dosing and purge steps on a representative nanofiber cross-section. Essentially, precursors are adsorbed at the surface in a sequence and they react to form a conformal coating. Figure $4 \mathrm{~b}$ depicts steps involved in obtaining various types of one-dimensional fibrous nanostructures, such as nanoparticle-decorated, core-shell, bishell, and so on. It also indicates the optional calcination process to remove the nanofiber core, which converts the nanofibrous structures into hollow nanofibers.

Challenges of Combining Electrospinning and Atomic Layer Deposition. Several critical challenges exist for an ideal conformal and uniform coating process on electrospun nanofiber template.

(i) Tuning the recipe to provide sufficient precursor diffusion time: In contrast to conventional ALD recipes, to ensure ultimate conformality on the large effective surface area of the nanofiber template, substantially long diffusion time intervals have to be incorporated in the deposition cycle of the material of interest. In order to do this effectively, the gate valve of the reactor chamber is closed right before the precursor pulsing so that maximum amount of precursor vapor is available for diffusing into the porous nanofibrous template. During this diffusion period, the chamber pressure is increased significantly mainly due to the pump isolation and continuous carrier gas flow. The increased chamber pressure might cause additional challenges in the reactor operation, where pressure gauges operate typically at lower pressures. This additional precursor diffusion step is increasing the unit ALD cycle significantly, resulting in extremely long deposition times.

(ii) Keeping the substrate temperature below polymer melting temperature: Despite being known as a lowtemperature deposition process, the low-temperature compatibility of polymeric materials pose an additional upper limit in substrate temperature to be used in ALD experiments. Typical deposition temperatures lower than $150{ }^{\circ} \mathrm{C}$ work for most of the polymers and ALD materials. However, some compounds might require higher temperatures for deposition, which would contradict with the temperature limits of the polymeric material used in electrospun nanofibers. In such a case, an alternative to further reduce the deposition temperature would be to employ plasma-ALD at the expense of possible plasma damage and reduced conformality. As an example for this solution approach, we have successfully synthesized AlN coatings on polymer nanofibrous templates by reducing the typical thermal-ALD temperature from $\sim 350{ }^{\circ} \mathrm{C}$ to less than $200{ }^{\circ} \mathrm{C}$ by using plasma-ALD. Due to the reduced deposition temperature, we were able to preserve the volumetric fibrous 
structure and obtain hollow nanofibers after the calcination process.

(iii) For plasma processes, to avoid plasma etching of the polymeric templates by energetic plasma species, protective layers should be used: Although being useful in reducing the ALD deposition temperature for compound materials, plasma processing comes with several critical shortcomings as well. First, the plasma damage factor might be severe for relatively easy to damage/etch polymeric materials. A possible direct mitigation measure for the plasma damage might be to reduce the rf-plasma power to minimize the incident energy of plasma species and to increase the chamber pressure in order to increase the number of collisions of plasma species, thereby again decreasing the energy of impinging plasma particles. Another indirect mitigation technique that can be used to protect the polymeric materials from degrading under plasma exposure is to use protective layers on the surface of electrospun nanofibers. Such protective conformal layers can be deposited within the same ALD reactor, prior to the plasma deposition process in thermal-ALD mode. Our group has extensively employed this methodology for the fabrication of flexible and hollow-core III-nitride nanofibers. Another significant drawback of plasma-ALD stems from the directional character of plasma processes: this mainly results in a nonideal conformal coating on high surface area nanoporous templates. This effect might be reduced to a certain degree by increasing the pressure inside of the chamber; however, the conformality performance would definitely not be as good as thermal-ALD processes.

\section{PHOTOCATALYSIS}

The photocatalytic performance of the nanostructures is explored over the degradation of organic pollutants under UV to visible irradiation. The energy of the illumination is mainly determined based on the band gap of the catalyst; however, defects within the band gap could be activated with relatively lower energy. Typically, ${ }^{108} 10 \mathrm{mg}$ of the catalyst is immersed in $25 \mathrm{~mL}$ solution of methyl orange $(10 \mathrm{mg} / \mathrm{L})$. For UV radiation, a $400 \mathrm{~W}$ light source with an emission wavelength range of $300-400 \mathrm{~nm}$ is employed for the experiments. The light source is kept at a distance of $10 \mathrm{~cm}$, and the solution is kept under UV light for $3 \mathrm{~h}$. A certain amount of sample is collected and centrifuged to eliminate the catalyst (if required), which is then subjected to UV-vis transmission spectroscopy. By tracing the intensity of a characteristic peak of the dye molecule with respect to UVexposure time, the concentration of the dye molecules is calculated. The photocatalyst is fabricated by depositing catalytically active material (metal oxide semiconductor) on top of the electrospun fibers. Wide band gap metal oxide semiconductors, such as $\mathrm{ZnO}$ and $\mathrm{TiO}_{2}$ and their combinations, were employed in different forms like core-shell, nanoparticles, or nanoclusters. They are mostly tested for catalytic activity through the photodegradation of organic molecules (methylene blue, rhodamine $\mathrm{B}$, methyl orange, etc.) in water. The degradation produces $\mathrm{CO}_{2}$ or $\mathrm{H}_{2} \mathrm{O}$ with $\mathrm{O}_{2}$ and various molecular fragments.

Comprehensive reviews on semiconductor based photocatalysts have appeared in the literature. ${ }^{115-117}$ Various studies on the photocatalytic applications of metal oxide coated electrospun fibers have been studied by our research group by combining electrospinning and ALD. ${ }^{4,35,45,46,68,82,109,118,119}$ In a typical example, core-shell nanofibers were produced where the core is nylon nanofibers while the shell is $\mathrm{ZnO}$ nanoparticles or nanolayers. ${ }^{109}$ As described earlier, a control on the thickness of the shell layer is achieved by varying the number of cycles in the ALD process. Hence, a transition from nanoparticles to a nanolayer with a thickness of $\sim 27 \mathrm{~nm}$ is achieved. The highest photocatalytic activity (PCA) was recorded when the nanoparticles densely cover the surface of the nanofibers, and the activity decreases as the density of the nanoparticle decreases. The enhanced catalytic activity was attributed to their higher catalytic surface area that increases the active sites. ${ }^{109}$ We have further investigated the influence of surface area of a semiconductor layer on the photocatalytic performance, ${ }^{109,119}$ where we varied the mean diameter of the core nanofiber $(\sim 80, \sim 240$, and $\sim 650 \mathrm{~nm})$ and keeping the thickness of the shell layer fixed $(\sim 90 \mathrm{~nm})$. The morphological and structural integrity were also investigated, and it is found that $\mathrm{ZnO}$ is polycrystalline with a hexagonal wurtzite structure. The nanofibers with the smallest mean diameter showed the highest catalytic performance owing to their higher specific surface area. ${ }^{120}$ Also, the sample could be reused without any significant decay in their PCA. Furthermore, we have improved the catalytic activity by growing $\mathrm{ZnO}$ nanoneedles (diameter, $\sim 25 \mathrm{~nm}$ and the aspect ratio of $\sim 24$ ) using the hydrothermal method on the surface of the nanofibers. ${ }^{4}$ These hierarchical nanostructures depicted an enhanced catalytic performance which was credited to the surface defects, while the needle structure supports the vectorial transport of photogenerated charge carriers. In connection to the defects, we have studied the intrinsic defect reorganization in $\mathrm{ZnO}$ and its effect on the photocatalytic performance with hollow $\mathrm{ZnO}$ nanofibers. ${ }^{45}$ $\mathrm{ALD}$ of $\mathrm{ZnO}$ with an average grain size of $\sim 20 \mathrm{~nm}$ is obtained on nanofibers of two different average diameters (80 and 650 $\mathrm{nm}$ ). The results revealed that increasing the surface area does not enhance the photocatalytic performance, rather the density of the surface defects play a crucial role. In the first glance, it might appear that the defect density is higher if the surface area is increased. However, indeed, there is a critical balance that one has to hit to obtain the highest PCA. Beyond a limit, the increased density of defects decreases the electronic quality, which decreases the quantum efficiency (photon to electron conversion ratio). Clearly, we need to optimize the electronic properties to obtain the highest performance. One of the ways to tune the electronic properties is "doping". Nasr et al. ${ }^{121}$ compared the PCA of $\mathrm{Al}_{2} \mathrm{O}_{3}$ doped $\mathrm{ZnO}$ nanotubes with that of undoped $\mathrm{ZnO}$. By changing the deposition sequences of the $\mathrm{Al}_{2} \mathrm{O}_{3}$ and $\mathrm{ZnO}$ cycles, $\mathrm{Al}_{2} \mathrm{O}_{3}$ doped $\mathrm{ZnO}$ nanotubes with different ratios of $\mathrm{Zn} / \mathrm{Al}$ were produced. This is rather a potential technique to produce doped semiconductor to increase the carrier concentration. Under UV irradiation, the PCA increased with increasing the ratio of $\mathrm{Al}_{2} \mathrm{O}_{3} / \mathrm{ZnO}$. Moreover, the nanotubes could be reused four times without any significant decrease in the catalytic activity. $\mathrm{Al}_{2} \mathrm{O}_{3}$ doping of $\mathrm{ZnO}$ can indeed decrease the resistivity and increase the carrier concentration. ${ }^{122}$ A higher carrier concentration might have increased the catalytic activity. This method could be applied to other semiconductors. Despite $\mathrm{TiO}_{2}$ being another important large band gap material, doped counterparts using ALD are not widely tested for the PCA. By given the stability 

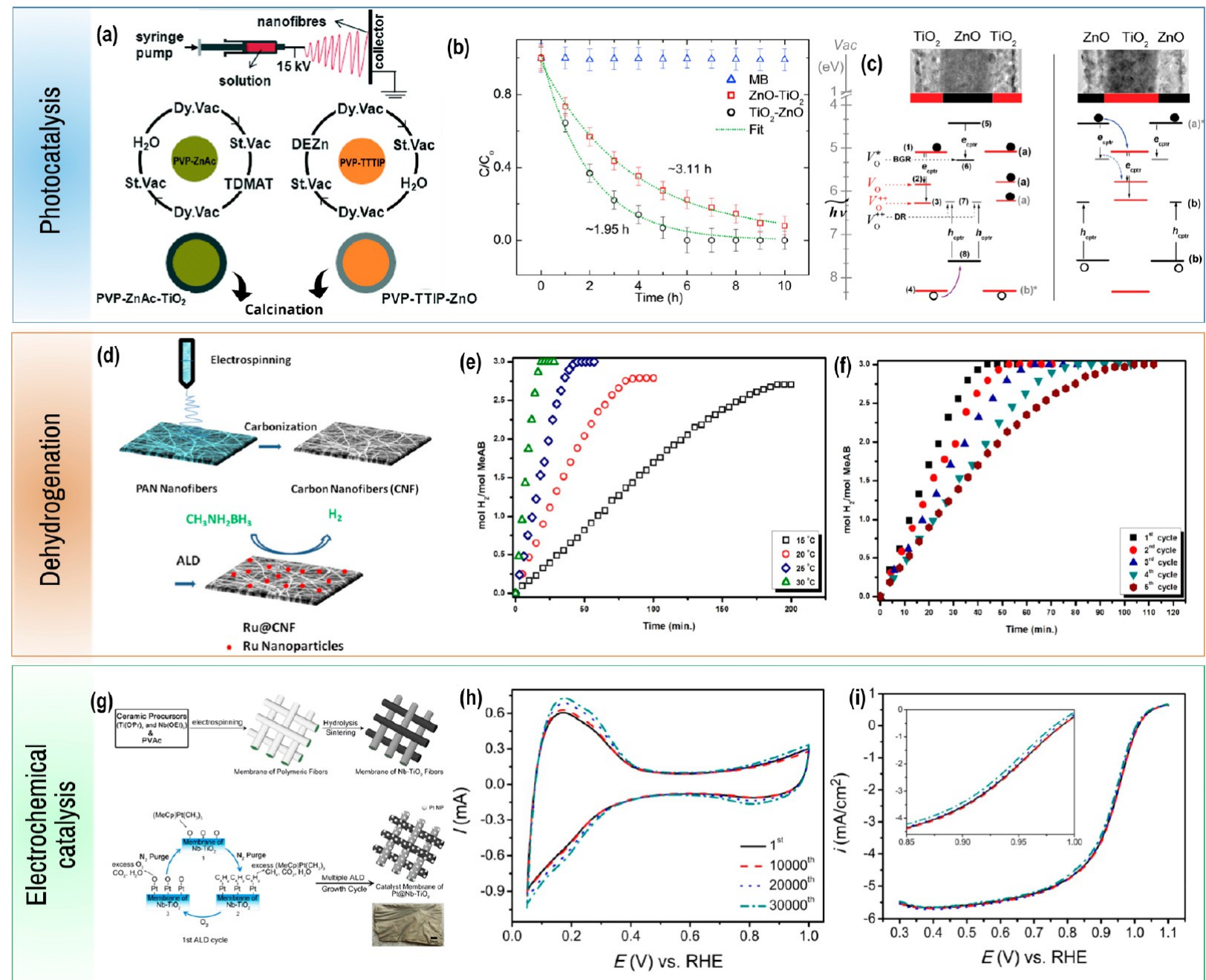

Figure 5. Applications of catalytic fibrous materials produced using both electrospinning and ALD. (a) Cartoon illustration of the production of core-shell heterojunction (CSHJ) nanofibers and (b) the $\mathrm{PCAs}$ of the $\mathrm{ZnO}-\mathrm{TiO}_{2}$ and $\mathrm{TiO}_{2}-\mathrm{ZnO}$ core-shell heterojunction nanofibers. Constants and exponential decay fits are depicted. (c) Proposed catalysis mechanism: electrons from the $\mathrm{TiO}_{2}$ are engaged from the $\mathrm{ZnO}^{-\mathrm{TiO}}{ }_{2}$ $\mathrm{CSHJ}$. The energetic band locations of $\mathrm{TiO}_{2}$ were taken from the literature. (d) Cartoon illustration of the production of catalytic ruthenium (Ru) nanoparticle decorated PAN carbon nanofibers for MeAB dehydrogenation and (e) plot showing the mole of the formed $\mathrm{H}_{2}$ per mole of MeAB versus time during the dehydrogenation of $\mathrm{MeAB}\left(c_{\mathrm{MeAB}}=100 \mathrm{mM}\right)$ catalyzed by $\mathrm{Ru} @ \mathrm{CNF}\left(c_{\mathrm{Ru}}=0.0135 \mathrm{mM}\right)$ at different temperatures, $(\mathrm{f})$ plot depicting the mole of formed $\mathrm{H}_{2}$ per mole of MeAB versus time for the 1st to 5th recycle in the $\mathrm{Ru} @ \mathrm{CNF}\left(c_{\mathrm{Ru}}=0.0135 \mathrm{mM}\right)$ catalyzing the dehydrogenation of $\mathrm{MeAB}\left(c_{\mathrm{MeAB}}=100 \mathrm{mM}\right)$ at RT. (g) Schematic illustration for the process for the fabrication of Pt@Nb-TiO $\mathrm{P}_{2}$ catalyst for ORR and the accelerated-stability test of $\mathrm{Pt} @ \mathrm{Nb}-\mathrm{TiO}_{2}$ catalyst having 10 at. \% $\mathrm{Nb}$ : (h) cyclic voltammetry curves and (i) ORR polarization curves measured at $1600 \mathrm{rpm}$. First, second, and third rows of this figure were reproduced from ref 46 (Copyright 2014 Royal Society of Chemistry), ref 118 (Copyright 2018 American Chemical Society), and ref 134 (Copyright 2014 American Chemical Society), respectively.

and applicability of $\mathrm{TiO}_{2}$, it is certainly a vital testing that still needs to be addressed.

Another important strategy to obtain higher PCA is to delay the recombination process of photogenerated electron-hole pairs through an internal electric field that arises due to band alignment. Szilagyi et al. reported $\mathrm{WO}_{3} / \mathrm{TiO}_{2}$ core $(140-300$ $\mathrm{nm})$-shell $(1.5,3.1,10$, and $19.3 \mathrm{~nm})$ nanofibers and explored their $\mathrm{PCA}^{113}$ with UV-vis or visible illumination. The nanofibers with $1.5 \mathrm{~nm}$ of the $\mathrm{TiO}_{2}$ layer showed the highest visible light catalytic activity. Catalytic activity is brought into the visible region through the $\mathrm{WO}_{3}$ core, where the visible light can penetrate through the thin and wide band gap $\mathrm{TiO}_{2}$ shell. The smart design of structuring wide and smaller band gap materials as shell and core, respectively, is notable. Also, $\mathrm{TiO}_{2}$ is relatively a more stable material under photocatalysis. This protects the core- $\mathrm{WO}_{3}$ material from degradation during the redox cycles. Santala et al. developed various approaches for the fabrication of catalysts. ${ }^{123}$ Apart from hollow tube and core $\left(\mathrm{NiFe}_{2} \mathrm{O}_{4}\right.$ or $\left.\mathrm{CoFe}_{2} \mathrm{O}_{4}\right)$-shell structures, authors have synthesized hollow tubes filled with $\mathrm{Fe}_{2} \mathrm{O}_{3}$ nanoparticles, where the shell structure is always $\mathrm{TiO}_{2} \cdot{ }^{123}$ The highest PCA was observed for $\mathrm{Fe}_{2} \mathrm{O}_{3}$ nanoparticle loaded $\mathrm{TiO}_{2}$ nanotubes. Due to the presence of magnetic particles, the catalyst could easily be recovered from the solution and reused. When the catalyst is nonmagnetic in nature, centrifugation is the only quick recovery option if the structural integrity of the catalytic membrane is not good enough. The incorporation of the magnetic nanoparticles not only saves the recovery time but also makes the process easier. PCA of $\mathrm{ZnO} / \mathrm{ZnAl}_{2} \mathrm{O}_{4}$ multiconcentric nanotubes was studied. ${ }^{108}$ In this case, the core-shell nanofibers were subjected to two stage calcination. With increasing the number of layers, the formation of defects, 
stimulation of nonradiative recombination, and/or surface charge transfer took place in the structures, which significantly enhanced the PCA. So far, it is clear that the electrons and holes take part in the PCA; however, the individual role of each of the excited state carriers in the catalysis is not known. In this direction, our group has employed a core-shell heterojunction nanostructure based on $\mathrm{TiO}_{2}$ and $\mathrm{ZnO}$ that can selectively expose either of the charge carriers to the environment (Figure 5a-c). ${ }^{46}$ Given the band alignment between the core and shell materials, electrons or holes are selectively exposed to the catalytic environment under appropriate illumination (Figure 5c). Essentially, when the shell is $\mathrm{TiO}_{2}$, electrons remain in the conduction band of $\mathrm{TiO}_{2}$ while the holes may migrate to the valence band of $\mathrm{ZnO}$. The electrons in the conduction band when available at the surface take part in the catalysis process. The converse is true if the shell layer is $\mathrm{ZnO}$ and the core is $\mathrm{TiO}_{2}$. Indeed, these kinds of catalysts must be tested for other synthesis applications where one requires predominantly electrons or holes in the reactions Apart from the excited state carriers, the defects at the surface also play a crucial role in determining the rate of PCA. At the $\mathrm{TiO}_{2}(\mathrm{ZnO})$ surface, electrons (holes) from the conduction (valence) band may be captured by oxygen vacancies. We found that the catalytic activity is 1.6 times higher when holes are involved in the catalytic activity, i.e., $\mathrm{TiO}_{2}-\mathrm{ZnO}$ coreshell heterojunction where lower mobility of holes and oxygen vacancies play a crucial role. ${ }^{46}$ In the case of the $\mathrm{TiO}_{2}-\mathrm{ZnO}$ core-shell heterojunction, the defect bound electrons and holes take part in the catalytic reaction, where the efficiency is limited by the recombination time-scale and their availability at the surface. The energy from the defect electrons could be captured, as shown by Aslan et al. with $\mathrm{Pd} / \mathrm{ZnO} /$ polyacrylonitrile nanofibers. ${ }^{35}$ In their study, ${ }^{35}$ anisotropic Pd nanocubes were attached by submerging the nanofibers in the dispersion of Pd nanocubes for $30 \mathrm{~min}$ and drying at $110^{\circ} \mathrm{C}$ for $5 \mathrm{~min}$. $\mathrm{Pd} / \mathrm{ZnO}$ nanofibers depicted better performance than that of $\mathrm{ZnO}$ nanofibers, which was attributed to both energy transfer between the $\mathrm{Pd}$ nanocubes and the $\mathrm{ZnO}$ nanolayer and plasmonic resonance excited by the defect electrons of the $\mathrm{ZnO}$ layer. ${ }^{35}$ The basic idea of capturing the photoexcited electrons and deploying them for PCA can be extended to other material combinations including noble metals such as $\mathrm{Au}$. Also, these noble metals can increase the applicability by taking part in metal catalyzed chemical reactions. Bechelany et al. reported the preparation of metal organic framework (MOFs) and projected their possible use in photocatalysis, where ultrathin oxide $\left(40-50 \mathrm{~nm}\right.$ thick $\mathrm{ZnO}$ and $\mathrm{Al}_{2} \mathrm{O}_{3}$ ) layers on PAN nanofibers were subjected to microwave-assisted solvothermal treatment. ${ }^{70}$ The characterization of the final product revealed a specific surface area of $S_{\mathrm{BET}}=1760 \pm 260$ $\mathrm{m}^{2}$ per gram while $\mathrm{ZnO}$ deposited PAN nanofibers have a specific surface area $\left(S_{\mathrm{BET}}\right)$ of $10 \mathrm{~m}^{2} / \mathrm{g}$. As discussed earlier, increasing the surface area of the catalyst is a vital task, where a balance needs to be achieved with respect to the surface defects so that the overall optical quality of the catalyst is not compromised. MOFs have grabbed serious research attention which, however, is not thoroughly exploited for PCA with hierarchical structure.

Reduction, Dehydrogenation, and Hydrolysis Reactions. Chemical transformation of small organic molecules is a rather important field of research, where nanostructures are widely applicable as catalysts. This is due to their higher specific surface area to volume ratio requiring a relatively smaller quantity of the catalyst with respect to their bulk counterparts. Celebioglu et al. studied the reduction of 4nitrophenol with core (polyacrylonitrile)-shell $\left(\mathrm{TiO}_{2}, 8 \mathrm{~nm}\right)$ decorated with Pt nanoparticles ( $2 \mathrm{~nm}$ mean diameter). ${ }^{124} \mathrm{It}$ is found that the deposition of a thin layer of $\mathrm{TiO}_{2}$ enhances the stability of the polymer and improves the attachment of $\mathrm{Pt}$ nanoparticles. Also, the nanofibers could be reused several times without any significant change in the fiber morphology at a degradation rate of $0.1102 \mathrm{~s}^{-1}$. In a recent study, $\mathrm{Pd}$ nanoparticles $(\sim 4 \mathrm{~nm}$ in diameter) are coated on top of crosslinked cyclodextrin nanofibers and employed for the hydrogenation of 4-nitrophenol. ${ }^{125}$ Khalily et al. studied hydrolytic dehydrogenation of methylamine borane (MeAB) with $\mathrm{Ru} /$ carbon nanofibers. ${ }^{118}$ The electrospun PAN nanofibers were carbonized and functionalized with Ru quantum dots of $3.4 \pm$ $0.4 \mathrm{~nm}$ (Figure $5 \mathrm{~d}$ ). The volume of hydrogen quantifies the catalytic activity which measured during the hydrolytic dehydrogenation of $\mathrm{MeAB}$ (Figure 5e). In a control measurement, Ru-free carbonized nanofibers depicted no catalytic activity. The rate constants $\left(k_{\mathrm{obs}}\right)$ for the reactions were, respectively, $0.00163,0.0458,0.0763$, and $0.2033 \mathrm{~mol} \mathrm{H}_{2} /(\mathrm{mol}$ $\mathrm{MeAB} \times \min )$ at $15,20,25$, and $30{ }^{\circ} \mathrm{C}$. Furthermore, the activation energy $\left(E_{\mathrm{a}}\right)$ for the dehydrogenation of $\mathrm{MeAB}$ by $\mathrm{Ru} @ \mathrm{CNF}$ was found to be $30.1 \mathrm{~kJ} / \mathrm{mol}$, which was much lower than most catalytic systems reported in the literature. Moreover, the catalytic stability of the Ru@CNF was evaluated over five repetitive cycles, and the nanofibers could completely convert the $\mathrm{MeAB}$ by retaining $72 \%$ of its intrinsic catalytic performance even at the fifth recycle (Figure 5f). In another study, ${ }^{126} \mathrm{TiO}_{2}$ hollow nanofibers were used to grow MOFs on the fibers through solvothermal synthesis. The resultant fibers were tested for the hydrolysis of methyl paraoxon where the formation of 4-nitrophoxide was observed by monitoring the UV-vis absorption band at $407 \mathrm{~nm} .{ }^{126} \mathrm{PVDF} / \mathrm{Ti}(\mathrm{OH})_{4}$ and $\mathrm{PMMA} / \mathrm{Ti}(\mathrm{OH})_{4}$ nanofibers were subjected to $200 \mathrm{ALD}$ cycles to form $\mathrm{TiO}_{2}$. Then solvothermal synthesis was employed for the synthesis of UiO-66- $\mathrm{NH}_{2}$ crystals. During the solvothermal process, the PMMA core was removed, leading to hollow fibers, while the PVDF core remained. Hollow fibers with MOF crystals have a specific surface area of $264 \mathrm{~m}^{2} \mathrm{~g}^{-1}$. Osman et al. produced catalytic PAN nanofiber functionalized nanoparticles of $\mathrm{ZnO}$ and $\mathrm{Pd}$ nanocubes for 2,4,6-trinitrotoluene (TNT) reduction (nitro groups of TNT into amine groups). ${ }^{127} \mathrm{Pd}$ nanocubes were coated on top of $\mathrm{PAN} / \mathrm{ZnO}$ nanofibers. Indeed, the catalysis using the nanostructures is limited to the conversion of small molecules. However, there is an unexplored and huge potential that exists with these nanostructured catalysts. The advantage is not just limited to the high surface area to volume ratio, it extends to higher density of surface bound active sites with multilevel hierarchical structures. Furthermore, the nanostructured catalysts can be recovered easily from the reactants. If suitably explored, we speculate that these catalysts find applications in biphasic interfacial reactions, where the catalytic membrane at the interface separates reactants and products into two different phases. Since the surface functional groups determine the hydrophilic and hydrophobic nature of the polymer, this could be a very good starting point.

Electrochemical Catalysis, $\mathrm{H}_{2} \mathrm{O}$ Splitting. Similar to photocatalysis, the activity of (photo)electrochemical catalysis crucially depends on the electronic properties of the catalyst in conjunction with carrier-concentration and its chemical potential with reference to the redox potential of water. It is 

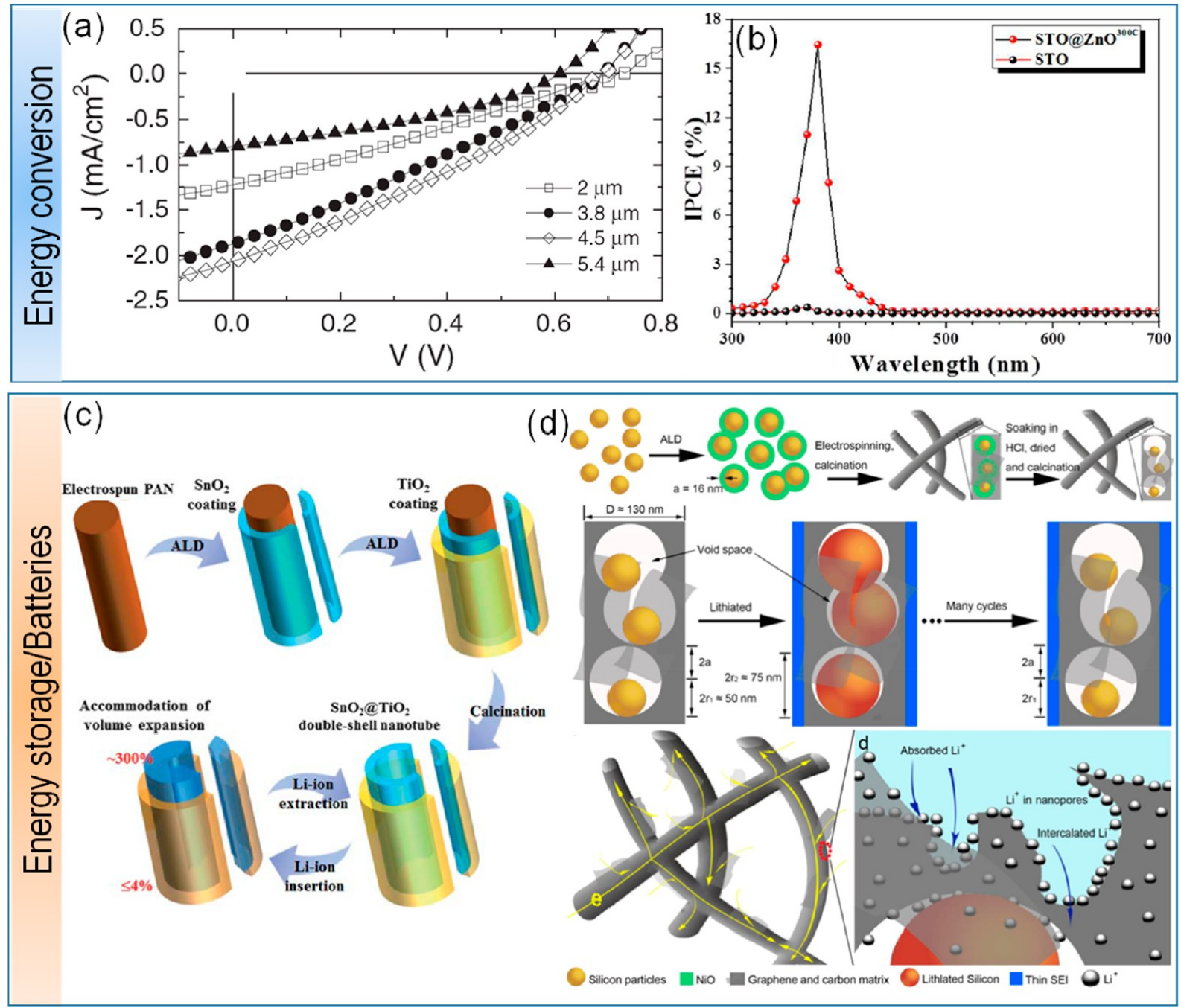

Figure 6. (a) $J-V$ characteristics of $\mathrm{TiO}_{2}$ nanofiber devices with four different $\mathrm{TiO}_{2}$ nanofiber layer thicknesses, from $2 \mu \mathrm{m}$ (open square), to 3.8 $\mu \mathrm{m}$ (solid circle), to $4.5 \mu \mathrm{m}$ (open diamond), and to $5.4 \mu \mathrm{m}$ (solid triangle). (b) Incident photocurrent conversion effciency (IPCE) curves for the bare $\mathrm{SrTiO}_{3}$ (STO) and STO@ZnO ${ }^{300 \mathrm{C}}$ photoanodes, where $\mathrm{ZnO}^{300 \mathrm{C}}$ indicates 300 cycles of ALD of $\mathrm{ZnO}$ on STO fibers. The presence of $\mathrm{ZnO}$ promotes the photon absorption and collection via the bandgap transition of STO. In addition, the IPCE reached a maximum of $\sim 16.43 \%$ at $\sim 380$ nm for the STO@ZnO hybrid photoanode, which is 44 times to that of bare STO at $\sim 370 \mathrm{~nm}$ (i.e., $\sim 0.37 \%$ ). (c) Schematic diagram depicting the synthesis of the $\mathrm{SnO}_{2} / \mathrm{TiO}_{2}$ double-shell nanostructure and lithium-ion insertion and extraction. Polyacrylonitrile nanofibers were subjected to ALD of $\mathrm{SnO}_{2}$ and then $\mathrm{TiO}_{2}$. The $\mathrm{TiO}_{2}$ outer shell maintains the structural integrity of the electrode during the charge-discharge cycles, where significant internal stress is expected due to the volume expansion. In fact, the hollow nature accommodates the volume expansion. (d) Synthesis and design of the 3D FSiGCNFs. (top row) Illustration of the synthesis process of the 3D FSiGCNFs. The 3D FSiGCNFs were soaked in hydrochloric acid solution to remove the $\mathrm{NiO}$ to form precise and controllable expansion space and annealed at $800{ }^{\circ} \mathrm{C}$ in $\mathrm{Ar}$ atmosphere for $2 \mathrm{~h}$. (middle row) Schematic diagram of the 3D FSiGCNF electrode design. Rationally designed FSiGCNFs with precise control of the expansion space by ALD, followed by electrospinning, were used as protection of Si NPs for flexible and binder-free lithium-ion batteries. The graphene/carbon matrix with excellent mechanical strength and electron transport properties not only achieves a superfast electron transfer but also provides enough space to buffer the volume changes of Si NPs during the lithium insertion and extraction reactions. In addition, the stable SEI forms outside of the graphene/carbon matrix rather than on the surface of Si NPs, which is attributed to the electrolyte being blocked by the hierarchical porous graphene/carbon matrix, while facilitating lithium transport throughout the whole structure. The 3D FSiGCNFs can keep the overall morphology, and the SEI outside the graphene/carbon matrix is not ruptured and remains thin after deep electrochemical cycles. Illustration of (bottom row) electron transmission and $\mathrm{Li}^{+}$storage in the 3D FSiGCNF film. Parts a, b, c, and d are reproduced from ref 36 (Copyright 2013 Elsevier), ref 67 (Copyright 2018 Royal Society of Chemistry), ref 56(Copyright 2013 Royal Society of Chemistry), and ref 44 (Copyright 2016 American Chemical Society), respectively.

important that the stability of the catalyst depends on the choice of the material where the chemical potential is an intrinsic property. Our research group recently tested $\mathrm{NiOOH} / \mathrm{Ni}(\mathrm{OH})_{2}$ decorated flexible carbonized PIM fibers. ${ }^{82}$ The fibers showed a low onset potential $\left(\eta_{\mathrm{HER}}=-40\right.$ and $\eta_{\mathrm{OER}}$ $=290 \mathrm{mV}$ vs RHE), small overpotential at $\eta$ at $10 \mathrm{~mA} \mathrm{~cm}{ }^{-2}$ (hydrogen evolution reaction $(\mathrm{HER})=-147 \mathrm{mV}$ and oxygen evolution reaction $($ OER $)=390.5 \mathrm{mV})$, outstanding kinetics

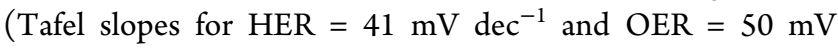
$\left.\operatorname{dec}^{-1}\right)$, and high stability (>16 h) for water splitting in $0.1 \mathrm{M}$ $\mathrm{KOH}$. MWCNT $/ \mathrm{TiO}_{2}$ nanofibers were also tested, ${ }^{128}$ where the current densities were found to be 5.1, 4.4, 2.6, 1.7, and 1.0 $\mathrm{mA} / \mathrm{cm}^{2}$ for $20,10,5,2$, and $0 \%$ of MWCNT in $\mathrm{TiO}_{2}$, respectively. Doping of a semiconductor increases the carrier 
concentration and may introduce in-gap states that could be used for visible light harvesting. ALD is a very promising technique for doping the wide band gap semiconductors, and a large scope is visible for future development of the catalysts for water splitting. Nitrogen doping of $\mathrm{TiO}_{2}$ is one such example. ${ }^{129}$ After doping, the hydrogen evolution capability and a 10 -fold improvement $(0.09$ to $0.8 \%)$ were observed in the photoconversion efficiency. Du et al. reported niobiumdoped titania-supported Pt catalysts $\left(\mathrm{Pt} @ \mathrm{Nb}-\mathrm{TiO}_{2}\right) .{ }^{130}$ First, niobium-doped titania $\left(\mathrm{Nb}-\mathrm{TiO}_{2}\right)$ nanofibrous membrane was produced using poly(vinyl acetate), titanium(IV) isopropoxide, and niobium ethoxide (Figure $5 \mathrm{~g}$ ). The nanofibers were pyrolyzed in air at $500{ }^{\circ} \mathrm{C}$ for $24 \mathrm{~h}$ to yield $\mathrm{Nb}-\mathrm{TiO}_{2}$ fibers. After the deposition of $\mathrm{Pt}$ nanoparticles of various sizes (depending on the applied ALD cycle), $\mathrm{Pt} @ \mathrm{Nb}-\mathrm{TiO}_{2}$ fibers were tested for the oxygen reduction reaction (ORR). The area-specific ORR activities of the catalysts rose from 0.0084 to $0.28 \mathrm{~mA} / \mathrm{cm}^{2}$ for $\mathrm{Pt} @ \mathrm{TiO}_{2}$ while it reached $0.9 \mathrm{~V}$ (vs RHE) when doped with 10 at. $\% \mathrm{Nb}$ (Figure 5h,i. The acceleratedstability test on the $\mathrm{Pt} @ \mathrm{Nb}-\mathrm{TiO}_{2}$ revealed a very high stability with $\sim 10 \%$ loss in activity. Recently, Khalily et al. reported $\mathrm{Co}_{3} \mathrm{O}_{4}$ nanocrystals $(\sim 3 \mathrm{~nm}$ mean diameter) decorated with nitrogen doped carbon nanofibers for ORR and oxygen evolution reactions (OER). ${ }^{131}$ An onset potential of $0.87 \mathrm{~V}$ with a Tafel slope of $119 \mathrm{mV} \mathrm{dec}{ }^{-1}$ was observed, which is close to the performance of a commercial $\mathrm{Pt} / \mathrm{C}$ catalyst. The turnover frequency value was calculated at an overpotential of $550 \mathrm{mV}$ to be $\sim 0.14 \mathrm{~s}^{-1}$, which is $\sim 15$ and 3-fold higher than those of the standard IrOx $\left(0.0089 \mathrm{~s}^{-1}\right)$ and bulk Co $\left(0.05 \mathrm{~s}^{-1}\right)$ catalysts. Further on, with the carbon nanofiber electrodes, recently, self-supported electrodes with $\mathrm{Ni} / \mathrm{NiO}$ and $\mathrm{Pd}$ nanoparticles are employed for HER/OER. ${ }^{132}$ The best CNF-Ni/NiO-Pd electrode displayed the lowest overpotential $\left(63 \mathrm{mV}\right.$ and $1.6 \mathrm{~V}$ at $\left.j=10 \mathrm{~mA} / \mathrm{cm}^{2}\right)$, a small Tafel slope $(72$ and $272 \mathrm{mV} / \mathrm{dec}$ ), and an exchange current density (1.15 and $22.4 \mathrm{~mA} / \mathrm{cm}^{2}$ ) during HER and OER, respectively. Notably, these electrodes consist of graphitic layers that cover and protect the $\mathrm{Ni} / \mathrm{NiO} \mathrm{NPs}$ from corrosion. Photo/electrochemical activity of the $\mathrm{TiO}_{2}$ surface is already well know. Indeed, $\mathrm{TiO}_{2}$ coated poly(acrylonitrile) fibers were employed for HER through biological species, viz, Escherichia coli. ${ }^{133}$ The $\mathrm{TiO}_{2}$ coated membranes were then functionalized with a [NiFe]-hydrogenase-containing membrane fraction from Escherichia coli. This hierarchical structure generates an organic film around the fiber mat which depicts the electrochemical activity for HER, where the current densities were more than $500 \mathrm{~mA} / \mathrm{cm}^{2}$ at $0.3 \mathrm{~V}$ overpotential.

\section{ENERGY: GENERATION AND STORAGE}

One of the methods to convert renewable energy to electric power is deploy solar cells. $\mathrm{Li}$ et al. ${ }^{36}$ compared the photovoltaic device performances of the $\mathrm{FTO} / \mathrm{TiO}_{2}-\mathrm{HBL} /$ $\mathrm{TiO}_{2}$-nanofibers-dye/P3HT/PEDOT:PSS/Au device structure, where $\mathrm{TiO}_{2}-\mathrm{HBL}$ (hole blocking layer) is prepared via ALD or spin-coating. Pinhole free structurally integral ALD$\mathrm{TiO}_{2}$ film depicted a relatively higher efficiency, due to reduced dark leakage current and increased charge carrier lifetime. See Figure 6a for JV curves from this DSSC. A number of studies employed electrospun nanofiber as active junction material, especially in dye sensitized solar cells (DSSCs). The applicability of electrospun nanofibers is due to the high surface area to volume ratio. However, the morphology that results from electrospun nanofibers consists of a large density of grain boundaries where the generated charge carrier could be trapped. This trapping could be detrimental for the efficiency of the device. Notably, the conformal coating that could be obtained from ALD is least explored when combined with the electrospun nanofibers. Much of the research focus is needed on how to reduce the grain boundaries through the ALD.

Apart from solar cells, photoelectrochemical splitting is another methodology to produce energy. As discussed earlier in the section Photocatalysis, impeding the $\mathrm{e} / \mathrm{h}$ recombination is essential for higher catalytic activity. Similarly, it is the case with photoelectrohcemical activity. For instance, the internal electric field between $\mathrm{SrTiO}_{3}$ (STO) nanofibers and ALD coated $\mathrm{ZnO}$ film hindered the $\mathrm{e} / \mathrm{h}$ recombination and enhanced the photoelectrochemical activity. This heterojunction, depicted a promising photocurrent stability of $\sim 61.3 \mu \mathrm{A} /$ $\mathrm{cm}^{2}$, which was $\sim 600$ times higher than that of the pristine STO homojunction counterpart $\left(0.12 \mu \mathrm{A} / \mathrm{cm}^{2}\right) .{ }^{67}$ See Figure $6 \mathrm{~b}$ for incident photon-to-current conversion efficiency with reference to the wavelength.

Energy that has been produced from the renewable natural sources (solar energy, wind energy) needs to be stored in the form of electrochemical energy with the help of batteries and supercapacitors. Earlier investigations ${ }^{37-44}$ aim at the development of new and next generation electrochemical energy storage technologies due to the ever increasing demand for energy. Over the current trend, lithium-ion batteries are promising power storage devices in the smart and portable electronic devices due to relatively higher specific power density which is rather an important factor for commercialization. This is where the high surface area to volume ratio of nanofibers plays a crucial role which can support higher current densities with three-dimensional architecture.

Generally, the development is focused on the construction of a new set of electrode materials or assemblies to produce efficient, stable, and cost-effective energy storage applications, where highly efficient electrochemical activity, shorter ionic path, and high electrical conduction are efficiency determining factors. ${ }^{44}$ Commonly, graphite based electrode systems are used as an anode material in lithium-ion batteries due to higher stability, good electrical conductivity, and relatively lower cost. Alternative anode-materials such as $\mathrm{MoS}_{2},{ }^{37} \mathrm{Sn},{ }^{38} \mathrm{Ge},{ }^{39}$ and carbon $^{38,40,41}$ have also been studied for lithium and sodium ion batteries. ${ }^{37-43}$ To improve the storage-efficiency, it is crucial to design a hierarchical nanoarchitecture, where the combination of electrospinning and ALD play a crucial role. Among the low-dimensional electrode materials, continuous 1D electrospun nanofibers have grabbed the attention as promising electrode materials with intriguing properties when compared with the electrode systems synthesized through other approaches. Also, electrospun nanofibers have an additional advantage such as scalability. ${ }^{27}$ Readers are encouraged to go through a comprehensive review that covers the secondary batteries based on electron spun nanofibers. ${ }^{27}$ The most important role of $\mathrm{ALD}$, in this case, is to produce highly conformal coatings $\left(\mathrm{TiO}_{2},{ }^{38,39} \mathrm{Al}_{2} \mathrm{O}_{3}{ }^{41,42}\right.$ ) that not only protect the active material from pulverization, cracking, etc. but also changes the surface functionality to the hydrophilic nature enhancing the electrolyte uptake. Furthermore, the $\mathrm{TiO}_{2}$ layer inhibits the reactions with lithium or sodium and enhances the stability of the electrodes. On the other hand, $\mathrm{Ru}^{40}$ and $\mathrm{Sn},{ }^{38}$ like heavy metals, are deposited in the form of nanoparticles on the surface of the protective coating ${ }^{40}$ or directly on top of the 
electrode $^{38}$ which in both cases the conductivity of the electrode increases. Normally nanoparticles are aggregated which results in the unstable specific surface area. This instability lowers the overall performance of secondary batteries, where relatively high capacitance and long-term stability are compromised.

Jean et al. ${ }^{114}$ studied an electrode material based on $\mathrm{TiO}_{2}$ $\mathrm{SnO}_{2}-\mathrm{TiO}_{2}$ trilayered tubular nanostructures. The electrode depicted high reversible stability of $\sim 550 \mathrm{~mA} \mathrm{~h} / \mathrm{g}$ even after 60 cycles at a current density of $\sim 50 \mathrm{~mA} / \mathrm{g}$. The sandwich architecture accommodated the mechanical stress during the charge-discharge cycles and improved the electrochemical properties. On the other hand, $\mathrm{SnO}_{2}-\mathrm{TiO}_{2}$ double shell nanotubes depicted stable and reversible capacity with higher current density than that of single $\mathrm{SnO}_{2}$ and $\mathrm{TiO}_{2}$ nanotube electrode assemblies. ${ }^{56}$ Figure $6 \mathrm{c}$ shows a schematic of lithium ion insertion and extraction. Electrospun Si-loaded carbon nanofibers with alumina coating were tested for electrochemical performance, and it is found that alumina coating increases the mechanical integrity, stability, and prevents any unwanted reactions between electrode and electrolyte. ${ }^{135}$ This is where the conformality of ALD is apparent. Furthermore, as expected, the thickness of the alumina determines the resistance to the transfer of charge. Also alumina coating improves the capacitance retention from $36.1 \%$ to $82.3 \%$ for 28 cycles of ALD when compared to that of uncoated $\mathrm{Si} / \mathrm{C}$ nanofibers. Zhu et al. ${ }^{44}$ developed a flexible anode for lithium ion batteries. In their report, a 3D architecture of flexible silicon and graphene/carbon nanofibers (FSiGCNFs) is studied where an atomic-scale control of the expansion space is obtained without any binder. Figure $6 \mathrm{~d}$ shows the detailed schematic of the fabrication and ion exchange process. During the charge-discharge cycles, $\mathrm{Si}$ nanoparticles depict volume expansion, where in FSiGCNFs the $\mathrm{Si}$ nanoparticles are surrounded by accurate and controllable void spaces. This readily increases the structural stability where the void spaces minimize any damage due to the volume expansion. This $3 \mathrm{D}$ porous structure with built-in void space between the $\mathrm{Si}$ and graphene/carbon matrix not only limits most solid electrolyte interface formation at the outer surface, instead of on the surface of individual NPs, and increases its stability. As a result, highly efficient channels were produced for the fast transport of both electrons and lithium ions during cycling. The electrochemical performance of FSiGCNFs is significant indeed, viz, $2002 \mathrm{mAh} \mathrm{g}^{-1}$ at a current density of $700 \mathrm{~mA} \mathrm{~g}^{-1}$ over 1050 cycles corresponding to $3840 \mathrm{mAh} \mathrm{g}^{-1}$ for silicon alone and $582 \mathrm{mAh} \mathrm{g}^{-1}$ at the highest current density of $28000 \mathrm{~mA} \mathrm{~g}^{-1}$.

A conformal coating of $\mathrm{Sn}$ on carbon nanofibers increased the conductivity, while $\mathrm{TiO}_{2}$ coating is employed as a protective coating. ${ }^{38}$ The pipe-wire form of $\mathrm{TiO}_{2}-\mathrm{Sn} @$ carbon resulted in relatively higher capacity. Also, more stable cycle performances are recorded with both lithium $(643 \mathrm{mAh} / \mathrm{g}$ at $200 \mathrm{~mA} / \mathrm{g}$ after 1100 cycles) and sodium ion $(413 \mathrm{mAh} / \mathrm{g}$ at $100 \mathrm{~mA} / \mathrm{g}$ after 400 cycles) batteries. $\mathrm{TiO}_{2}$ coated germanium and graphene composites are tested for efficiency as anode materials. ${ }^{39}$ The specific capacity of $\mathrm{TiO}_{2}$ coated composite is $1050 \mathrm{~mA} \mathrm{~h} / \mathrm{g}$ (100th cycle) and $182 \mathrm{~mA} \mathrm{~h} / \mathrm{g}$ (250th cycle) for the lithium and sodium ion batteries, respectively. These values have shown significant improvement from pristine germanium and germanium/graphene nanofibers. Ru-nanoparticles/ $/ \mathrm{TiO}_{2}$ on nitrogen doped carbon nanofibers depicted higher mass transport and electrical conductivity while $\mathrm{Ru}$-nanoparticles increased the round-trip efficiency. ${ }^{40}$ Theoretical results indicated that $\mathrm{Ru}$ and $\mathrm{TiO}_{2}$ enhance the electron transport capacity of $\mathrm{Li}_{2} \mathrm{O}_{2}$ when compared to that of pristine carbon nanofiber network. Among $\mathrm{TiO}_{2} / \mathrm{MoS}_{2}$ and pristine $\mathrm{MoS}_{2}$ nanofibers, ${ }^{37}$ the latter depicted an efficient discharge capacitance of $840 \mathrm{~mA} \mathrm{~h} / \mathrm{g}^{2}$ at the second cycle and the excellent rate capacity than that of bulk $\mathrm{MoS}_{2}$. Also, $~ 30 \%$ retention capacity is observed. Here, $\sim 4 \mathrm{~nm}$ of $\mathrm{TiO}_{2}$ film protects the sulfur dissolution during the cyclic process; however, the authors observed some reduced storage capacitance and increased retention (up to $\sim 64 \%$ ) after 30 cycles. Apart from the expensive lithium based battery technologies, sulfur-based systems have been tested owing to the advantages of lower cost, acceptable energy density, and sustainability. ${ }^{41,43} \mathrm{Fe}_{2} \mathrm{O}_{3}$-carbon nanofibers were subjected to vapor phase sulfidation at $600{ }^{\circ} \mathrm{C}$ under vacuum to produce $\mathrm{FeS}_{2}$-carbon nanofibers for Li-S batteries (electrolytes: conventional carbonate electrolyte and a "solvent-in-salt"-type). ${ }^{41}$ Due to vacuum and thermal processing, the electrode surface is now binder-free and depicted a cycling stability (working voltages with reference to $\mathrm{Li} / \mathrm{Li}^{+}$) of $1.5-3.0 \mathrm{~V}$ with carbonate electrolyte and in solvent. When the surface is coated with $50 \mathrm{~nm}$ of $\mathrm{Al}_{2} \mathrm{O}_{3}$ on the $\mathrm{FeS}_{2}$-carbon nanofiber, the cycling stability of the Li-FeS $\mathrm{S}_{2}$ system is increased to $1.0-3.0 \mathrm{~V}$ along with the high discharge energy density at both the material level $(\sim 1300 \mathrm{Wh} / \mathrm{kg})$ and electrode level $(\sim 1000 \mathrm{Wh} / \mathrm{kg})$. In another example, porous $\mathrm{C} / \mathrm{BaTiO}_{3}$ nonwoven nanofibers were initially stabilized at $280{ }^{\circ} \mathrm{C}$ for $4 \mathrm{~h}$ in air and then carbonized at $900{ }^{\circ} \mathrm{C}$ for another $6 \mathrm{~h}$ at $2 \mathrm{~K} / \mathrm{min}$ heating rate under $\mathrm{N}_{2}$ atmosphere. Then the porous $\mathrm{C} / \mathrm{BaTiO}_{3}$ mats were treated with sulfur powder (heated to $160{ }^{\circ} \mathrm{C}$ for $10 \mathrm{~h}$ under vacuum and then raised to $260{ }^{\circ} \mathrm{C}$ for $1 \mathrm{~h}$ in an Ar-filled tubular furnace) followed by ALD coating of $\mathrm{TiO}_{2}$. The heterostructure depicted discharge capacitances of 524.8 and $382 \mathrm{~mA} \mathrm{~h} / \mathrm{g}$ after 1400 at $1 \mathrm{~A} / \mathrm{g}$ and 3000 cycles at $2 \mathrm{~A} / \mathrm{g}$, respectively. This results from the inhibition of the volume expansion and shuttle effect, effective utilization of the active material, and formation of an interface with stable ionic transport channels. Yan et al. ${ }^{3}$ compared various methods of synthesis of $\mathrm{V}_{2} \mathrm{O}_{5}$ and found that the electrospun $\mathrm{V}_{2} \mathrm{O}_{5}$ nanofibers depicted relatively higher specific capacitance of $190 \mathrm{~F} / \mathrm{g}$ in aqueous electrolyte $(2 \mathrm{M} \mathrm{KCl})$ and $250 \mathrm{~F} / \mathrm{g}$ in organic electrolyte $\left(1 \mathrm{M} \mathrm{LiClO}_{4}\right)$ with energy densities of 5 $\mathrm{Wh} / \mathrm{kg}$ and $78 \mathrm{Wh} / \mathrm{kg}$, respectively. ${ }^{136}$ The specific capacitance is comparatively lower (150 F/g in aqueous electrolyte) when $\mathrm{V}_{2} \mathrm{O}_{5}$ is loaded on top of a carbon fiber as a composite. Also, the energy density turned out to be lower, viz, 18.8 Wh/ $\mathrm{kg} .{ }^{137}$ With the lack of commercial devices, indeed applicationoriented process research requires more attention so that the viable techniques such as electrospinning and ALD will lead to a commercial device, however, with not undermining the fundamental research. Notably, commercialization of such energy storage devices requires multistage research on various aspects. It is ideal to implement industrial research projects so that the researchers while perusing a scientific idea would be able to extend the thought process until the stage of commercialization.

\section{GAS SENSORS}

The nanostructured form of hierarchical 1D assemblies of wide band gap semiconductors such as $\mathrm{ZnO}, 50,51,57,60,61,138-140$ $\mathrm{SnO}_{2},{ }^{65,111,140} \mathrm{TiO}_{2},{ }^{50,51,57}$ including $\mathrm{CuO}$ (ref 112) depicted unique surface functionalities and higher sensitivities toward ethanol, ${ }^{138} \mathrm{O}_{2}$, $1,60,140 \mathrm{NO}_{2},{ }^{57,60,65,139,140} \mathrm{CO},{ }^{57,60,65,112,139}$ 


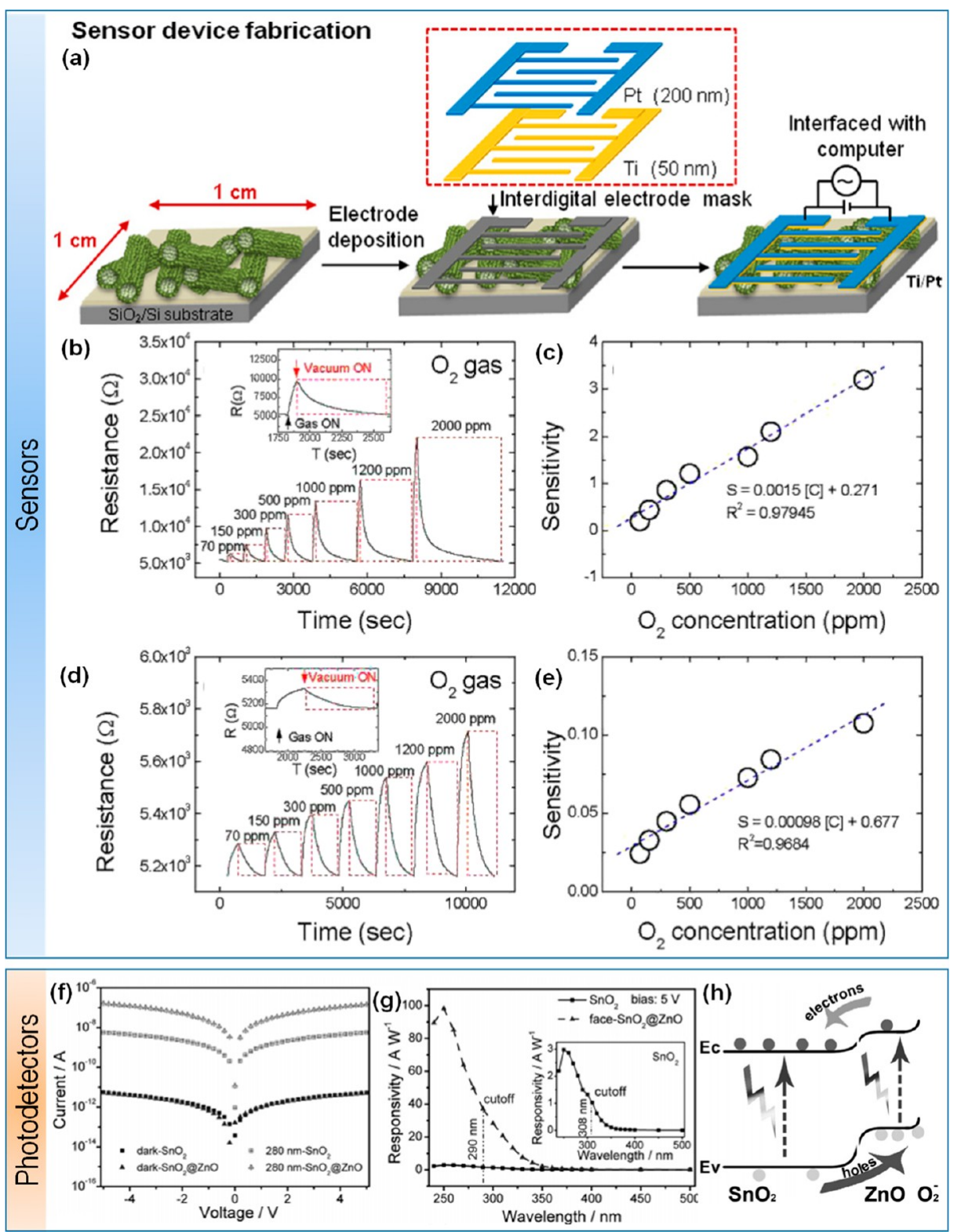

Figure 7. (a) Schematic process of fabrication of a sensor device with $\mathrm{ZnO}$ hollow fibers on $\mathrm{SiO}_{2} / \mathrm{Si}$. The interdigital electrode pattern $\mathrm{Ti} / \mathrm{Pt}$ is deposited on top of $\mathrm{ZnO}$ hollow fibers. The electrical characteristics are recorded with reference to the concentration of the test gas. (b) Dynamic response of the $\mathrm{ZnO}$ nanofiber based sensor to $\mathrm{O}_{2}$. The inset is the enlarged part of the data obtained at 300 ppm of $\mathrm{O}_{2}$. (c) Variation of sensitivity as a function of $\mathrm{O}_{2}$ concentration. Electro optical response of the $\Omega$-shaped $\mathrm{SnO}_{2} @ \mathrm{ZnO}$ based photodetector is shown from parts $\mathrm{f}$ to h. (f) IV curves from the $\mathrm{SnO}_{2}$ and $\mathrm{SnO}_{2}-\mathrm{ZnO}$ under illumination of $280 \mathrm{~nm}$ wavelength light compared with that of the dark. The $I V$ curves almost overlap across the two types of devices, while the photocurrent depicted a significant difference. The hybrid structure reaches $0.1 \mu \mathrm{A}$ at $5 \mathrm{~V}$. (g) Spectral responsivity is compared across $\mathrm{SnO}_{2}$ and $\mathrm{SnO}_{2} @ \mathrm{ZnO}$ photodetectors. The hybrid detector is $\sim 30$ times more responsive than the pure $\mathrm{SnO}_{2}$ counterpart with a shift of cut off wavelength to $290 \mathrm{~nm}$ from $308 \mathrm{~nm}$. The observed improvements are attributed to their type-II band alignment and built-in electric field as shown in part h. Under UV illumination, electrons tend to move into $\mathrm{SnO}_{2}$ while holes to the $\mathrm{ZnO}$ shell. Part a, parts $\mathrm{b}-\mathrm{e}$, and parts $\mathrm{f}-\mathrm{h}$ are reproduced from ref 60 (Copyright 2014 Institute of Physics), ref 140 (Copyright 2009 Institute of Physics), and ref 53(Copyright 2017 John Wiley and Sons), respectively.

$\mathrm{NH}_{3},{ }^{50,65} \mathrm{H}_{2},{ }^{65,111}$ etc. The basic principle of gas sensing is as follows. In the case of semiconductors, when the gas molecule adsorbs at the surface, the free electrons (hole) in the conduction band (valence band) may be captured by the gas molecule and/or adsorbed at the defect. The shift of charge can be partial or complete depending on the adsorbing species and availability of the unoccupied states. Since the carrier density is decreased upon adsorption, a change in the conductivity could be expected. As the concentration of the test gas molecule increases, the trapped charge density also increases, thus the conductivity decreases. A calibration curve is obtained by recording the change in the electrical conductivity with reference to the concentration of the test gas, from which the sensitivity can also be calculated. A schematic of a typical gas sensor is shown in Figure 7a. Despite the whole process appearing to be simple, the dynamics of adsorption and desorption and the mechanism of sensing determine not only the selectivity and sensitivity but also the time-based response. Since the adsorption and desorption 
processes are required to take place sequentially, the sensors are operated at relatively higher temperatures.

Ethanol sensitivity is tested on the tubular assembly of $\mathrm{ZnO}$ nanostructures while varying the thickness of the shell and the operating temperature. ${ }^{138}$ The lower the thickness of the wall, the better the responsivity when tested within a thicknessrange of $10-50 \mathrm{~nm}$. Authors report that for a sample of a 10 $\mathrm{nm}$ thick shell, the surface is completely depleted and thus they observed the highest response to the rest of the vapor at a sensing temperature of $450{ }^{\circ} \mathrm{C}$. Further into the sensing, $\mathrm{O}_{2}$, $\mathrm{NO}_{2}$, and $\mathrm{CO}$ gases have been tested on $\mathrm{ZnO}$ nanotubes, where the sensitivity of the sensor to $\mathrm{CO}$ gas depends on the thickness of the shell, ${ }^{60}$ however, better than that of $\mathrm{ZnO}$ nanofibers. $^{61}$ The calcination temperature (determines its crystallinity) at which the process of transforming the coreshell nanofiber into the tube (sacrificial polymer core) also plays a crucial role. The formation of nanograin assemblies in the fiber-network is the key for higher sensitivity. Other studies ${ }^{139}$ have focused on the diameter of the nanotube (fixed wall thickness of $\sim 60 \mathrm{~nm}$ ) on the sensitivity toward $\mathrm{CO}$ and $\mathrm{NO}_{2}$ exposure. At a critical thickness of the wall, high selectivity is observed with $\mathrm{CO}$ gas over $\mathrm{H}_{2}$, benzene, and toluene gases. $\mathrm{SnO}_{2}$ nanotubes were studied for sensitivity of ethanol over $\mathrm{H}_{2}, \mathrm{CO}, \mathrm{NH}_{3}$, and $\mathrm{NO}_{2}$ gases, ${ }^{65}$ where the thickness of the shell wall has been varied from 8 to $37 \mathrm{~nm}$. Twisting the sacrificial PAN nanofibers and depositing the $\mathrm{SnO}_{2}$ layer resulted in $\mathrm{SnO}_{2}$ nanotube microyarns. ${ }^{111}$ A stable and reversible $\mathrm{H}_{2}$ response is obtained for a diameter of 500 $\mathrm{nm}$ and a wall thickness of $70 \mathrm{~nm}$. The width of the depleted and undepleted regions determine the change in the resistance of the device and hence the sensitivity.

ALD of two different inorganic materials $\left(\mathrm{TiO}_{2}\right.$ and $\left.\mathrm{ZnO}\right)$ on a sacrificial electrospun nanofiber yields double layered hollow nanofibers (see Table 1). These heterostructures were tested for gas sensitivity with $\mathrm{CO}$ and $\mathrm{NO}_{2}$ as a function of thickness of the shell. ${ }^{57}$ The results suggested that the double layer hollow fibers were more efficient than that of hollow fibers in terms of sensitivity toward reducing gases, however, quite lower responses for oxidizing gases. Core-shell structured $\mathrm{TiO}_{2}-\mathrm{ZnO}$ nanofibers depicted better sensing response toward $\mathrm{NH}_{3}$ than that of $\mathrm{ZnO}-\mathrm{TiO}_{2}$ due to higher sensitivity of the $\mathrm{ZnO}$-shell. ${ }^{50}$ On the other hand, $\mathrm{SnO}_{2}-\mathrm{ZnO}$ based core-shell nanofibers were tested for $\mathrm{O}_{2}$ and $\mathrm{NO}_{2}$ sensitivities which performed better than pristine $\mathrm{ZnO}$ nanofibers. ${ }^{140}$ The time-dependent response of $\mathrm{SnO}_{2}-\mathrm{ZnO}$ in the presence of $\mathrm{O}_{2}$ is shown in Figure $7 \mathrm{~b}-\mathrm{e}$ for various gas concentrations. Core-shell $\mathrm{TiO}_{2}-\mathrm{ZnO}$ nanofibers were tested for $\mathrm{O}_{2}$ sensing. ${ }^{51}$ When $\mathrm{O}_{2}$ is adsorbed at the surface on the $\mathrm{ZnO}$ layer, the depth of the surface depletion layer changes and that is reflected in the resistivity. An ultrathin shell $(\sim 10$ $\mathrm{nm}$ ) of $\mathrm{ZnO}$ on the $\mathrm{SnO}_{2}$ nanofibers resulted in a notable sensing response and selectivity over their pristine counterparts, where the selectivity was associated with the depletion layer at the surface. ${ }^{141}$ The improvement in the sensing performance may be attributed to the formation of a heterointerface, surface depletion layer and the internal electric field created at the interface. Core-shell structured $\mathrm{CuO}(p$ type) and $\mathrm{ZnO}$ (n-type) was tested for $\mathrm{CO}$ gas sensing. ${ }^{112}$ As in the case of tubular nanostructures, , $^{500,139}$ the thickness of the surface $\mathrm{ZnO}$ layer and the width of the depletion layer is vital to determine the responsivity. This core-shell structure depicted a low sensing detection limit than that of pristine $\mathrm{ZnO}$ and $\mathrm{CuO}$ nanofibers. By an appropriate choice of the thickness of the active layer/the top $\mathrm{ZnO}$ layer, ${ }^{60,139}$ a relatively higher sensitivity to the reducing gas may be obtained. The thickness of the shell modulates the depth of the depletion layer radially ${ }^{142}$ and can also influence the response time. ${ }^{50}$ Nevertheless, the response of the $\mathrm{ZnO}$ based sensor to $\mathrm{O}_{2}$ is inherently a slow process, where the oxygen can be adsorbed at the surface as well as at the defect sites, capturing an electron from the conduction band or defect site, respectively. Release of defect-bound-oxygen requires a free hole in the valence band which could be mediated by a photon of suitable energy. Indeed a sensor based on the spectral response will be discussed. By producing $\mathrm{ZnO}$ of higher optical quality or lesser oxygen vacancies through ALD, we may expect a faster response from the sensor. Despite a potential material spectrum that ALD is capable of, only a limited number of materials are tested for sensitivity by producing hierarchical structures. There is a lot of scope in the context of Schottky junctions where one can expect faster response and better selectivity. The functionality of the earlier discussed gassensors depends on the change in the electrical resistivity due to the presence of the test gas molecule. Instead of electrical means, interestingly, Viter et al. ${ }^{143}$ investigated gas-detection by monitoring the photoluminescence (PL) of $\mathrm{ZnO}-\mathrm{PAN}$ nanofibers. By monitoring the ratio of intensities from near band edge emission (NBE) and deep level defect emissions (DLE), the concentrations of the volatile organic compounds are detected. Ethanol vapor (150 ppm) caused 20\% and 30\% for NBE and DLE intensity variations, respectively. This sensitivity is indeed relatively low when compared to the sensors based on variation in the conductivity. The sensitivity of this particular sensor depends on the simultaneous intensity of the two peaks in the PL spectrum, and this device may be suitable for recognition of different volatile organic compounds. Viter et al. ${ }^{143}$ also showed that the PL signal is stronger from $\mathrm{ZnO}-\mathrm{PAN}$ nanofibers than that of $\mathrm{ZnO}$ on $\mathrm{Si}$ substrate for the same quantity of the $\mathrm{ZnO}$ due to a large improvement in the specific surface area of the nanofibers. A spectrographic approach to gas sensors is know, and most of the studies use electrical signal to sense a test gas. The easiness in operation of gas sensors based on an electrical signal is completely acknowledged. However, when the device response is either low or slow, one might explore the possibility of a spectroscopic approach for improved results. Notably, the nanostructures act as waveguides increasing the detection efficiency.

\section{PHOTODETECTORS}

UV response from wideband semiconductors, such as $\mathrm{ZnO}$, $\mathrm{TiO}_{2}, \mathrm{SnO}_{2}$, etc., has been extensively studied in their pristine form as well as in heterointerfaces. ${ }^{53,64,110,144}$ For instance, nanotubes of $\mathrm{ZnO}$ [ref 144] and $\mathrm{TiO}_{2}$ [ref 64] were employed as active materials in detectors, while the heterointerfaces include $\mathrm{BiVO}_{4}-\mathrm{ZnO}^{110}$ and $\mathrm{SnO}_{2}-\mathrm{ZnO} .^{53}$ Upon UV-illumination, the absorbed photons create electron-hole pairs. A certain fraction of these electron-hole pairs may form excitons followed by recombination which does not change the free carrier concentration. However, on the other hand, the free carriers, including dissociated excitons, transiently increase the carrier concentration. The change in the free carrier concentration increases the conductivity resulting in an electrical signal. This is the basic detection mechanism of a photon in a photodetector. Chaaya et al. ${ }^{144}$ reported the sensitive and stable $\mathrm{UV}$ sensing properties of $\mathrm{ZnO}$ nanotubes 
and studied the effects of process parameters such as the temperature of the substrate and electrospinning-time. Authors reported that the sensor depicted promising stability over multiple consecutive on-off cycles with a constant recovery time. In this context, the mechanism of interaction between surface defects and adsorbed gas molecules should be taken into account when above band gap illumination of catalytically active surfaces such as $\mathrm{ZnO}$ takes place, i.e., gas sensing mechanism under UV illumination. $\mathrm{TiO}_{2}$ and $\mathrm{ZnO}$ are vastly employed UV-sensing elements, where the effects of UV light on the defect chemistry of $\mathrm{ZnO}$ is rather complex. ${ }^{145}$ Prolonged exposures to UV light affect surface and bulk defects through catalytic activity of $\mathrm{ZnO}$ on the adsorbed species and surface contaminants. Essentially, the electronic properties continuously change, which may not be the ideal scenario for photodetector applications, where change in the electrical conductivity is quantified against the photon intensity. Thus the calibration curve needs to be recalibrated. One can also think of passivating the thoroughly cleaned surface with insulating materials such as $\mathrm{Al}_{2} \mathrm{O}_{3}$ via ALD. Such coatings transmit the UV-light and hinder the surface adsorption of relatively larger molecular species. On the other hand, other wide band gap materials could also be considered.

In the context of heterostructures, Hou et al. ${ }^{110}$ reported on the UV response of the $\mathrm{BiVO}_{4}-\mathrm{ZnO}$ heterostructure. The photocurrent density of $\sim 0.46 \mathrm{~mA} \mathrm{~cm}^{-2}$ (at $1.23 \mathrm{~V}$ vs RHE) was observed under simulated sunlight irradiation, which is nearly 15.3 times higher than that of pristine $\mathrm{BiVO}_{4}$ nanoribbons. As discussed earlier, the built-in electric field (type-II) at the heterointerface enhanced the lifetime of the excited state carrier and separation rate of the excitons into free carriers. Note that the same strategy is applied on various other applications as discussed earlier. A further increase in the thickness of $\mathrm{ZnO}$ causes photocorrosion during the photochemical reaction. Hu et al. ${ }^{53}$ has reported the construction of $\Omega$-shaped hybrid (type-II) $\mathrm{SnO}_{2}-\mathrm{ZnO} \mathrm{UV}$ detectors through the ALD of $\mathrm{ZnO}$ on $\mathrm{SnO}_{2}$ nanofibers. The visibly transparent $\mathrm{SnO}_{2}-\mathrm{ZnO}$ heterostructure exhibited a relatively higher photoresponsivity ratio of $3.6 \times 10^{-4}$ at $280 \mathrm{~nm}$ which is $\sim 30$ times higher than that of pristine $\mathrm{SnO}_{2}$ nanofibers. Also wavelength selectivity of $2.0 \times 10^{3}$ (UV-vis rejection ratio, $250-400 \mathrm{~nm}$ ) is achieved by changing the direction of incident light. The $\Omega$-shaped nanostructure increases the photon gain and trapping with faster electron-hole pair separation. IV curves, wavelength dependent responsivity, and band alignment between $\mathrm{SnO}_{2}$ and $\mathrm{ZnO}$ are shown in Figure $7 \mathrm{f}-\mathrm{h}$, respectively. The waveguide nature of the nanostructures is a fundamental capability that could be harnessed in photodetectors, where there are a limited number of studies in this direction. At a specific wavelength, indeed, the wave guiding nature depends on the size of the nanostructures. Given the fact that it is difficult to obtain nanofibers of a uniform diameter with electrospinning, wave guiding at a specific wavelength would not be very easy. However, statistically, there are always some nanofibers which fall within the range of interest.

\section{OUTLOOK AND CONCLUSION}

The potential to obtain hierarchical nanostructures from the combination of electrospinning and ALD are exemplified in this review. However, much larger scope is available for further developments where, postprocessing or other growth techni- ques (e.g., hydrothermal, ${ }^{4}$ solvothermal, ${ }^{126}$ ) could be employed on the nanostructures that were synthesized via combining electrospinning and ALD, e.g., metal-organic framework was grown on the nanofibers by the solvothermal technique. ${ }^{70}$ However, these specific nanostructures were not subjected to any of the catalytic or other relevant applications.

In the context of catalysis, degradation of the organic pollutant with inorganic catalyst is a smaller aspect of photocatalysis. The usage of photocatalyst in chemical reactions derived from this combination is still under exploitation given the fact that the catalysts could be produced in bulk quantities for industry. Also, the majority of the studies track the peak that is the characteristic of the organic pollutant. However, once the molecule fragments due to catalytic reactions, a complete degradation of the molecule is not traced. This will help us to understand the catalytically active site with reference to the adsorption configuration and molecular size. Furthermore, the BET surface area is extensively used to quantify the available surface area. However, all of these sites where $\mathrm{N}_{2}$ adsorbs may not be available for the catalysis, where the molecule has to come to the site as close as $1 \AA$. Given the fact that the organic dye molecules are larger, a small molecule like $\mathrm{N}_{2}$ may be adsorbed at several places which are not catalytically active. The detailed and fundamental insights are still not completely available for various catalysts and reactants. Studies in this direction will definitely increase the industrial applicability of these catalysts.

Electrospinning and ALD could yield nanostructures of various materials which are not yet explored to their full potential toward solar cell applications. In principle, carefully processed nanofibers could form very good electron transporting channels, while the ALD can produce pinhole free conformal coatings of HBL layers. In fact, in energy storage applications, the electron transport through fibers is exploited. Notably, in general, the inorganic nanofibers consist of smaller grains, while the very nature of higher surface area to volume ratio increases the surface defects including grain boundaries. These grain boundaries and surface defects may be scattering/ trapping centers for the charge carriers. This is beneficial for the catalysis; however, not for solar cells. Having said that, conformal coatings yielded from ALD could be studied for the passivation of such defect sites. ${ }^{53}$ In the context of energy storage, a great deal of developments have taken place on the development of next generation anode materials for lithium and sulfur based batteries as well. On the other hand, in relation to gas sensors, relatively higher surface area to volume ratio yields higher gas sensitivity. The adsorption and desorption kinetics need to be considered in conjunction with the choice of material and the test gas, where extensive literature is available. Various hybrid structures have been studied toward photodetectors. Nevertheless, the capabilities of combination of ALD and electrospinning are under explored toward wavelength selective photodetectors, and we believe that there exists a lot of scope for the development of other novel hybrid nanostructures. For instance, a wide band gap semiconductor such as $\mathrm{ZnO}$ has been used as an active material in UV-detectors; however, it suffers from lower response time which is generally attributed to the adsorption/ desorption of molecular oxygen due to UV exposure apart from various other effects as discussed by our group earlier. ${ }^{146}$ In this particular example, perhaps passivation schemes could be explored to enhance the performances of the device, where the conformal coating obtained from ALD might provide a 
solution. ${ }^{53}$ There are various other semiconductors that could be produced through electrospinning; however, they are not explored for their wavelength-selective detection performances.

Electrospun nanofibers act as a substrate and adsorb the ALD-precursor material. The quality of the interface is determined by the surface diffusion/infiltration of subsequent precursors. Indeed further experiments and analysis are required featuring high-resolution electron microscopy to image the immediate polymer/ALD coating interface. As an aside, notably, such an infiltration process (surface infiltrated synthesis) is actually being utilized to obtain composite organic/inorganic patterned films with potential applications in lithography-free nanofabrication. To conclude, ALD has become a common approach in catalysis for the deposition of metals and metal oxides on the one-dimensional nanofibrous electrospun templates to allow their reusability and facile recycling while enhancing their catalytic activity due to the chemical decoration of catalysts in an atomically controlled manner. The density and type of deposition of metal atoms can easily be adjusted by the changing the cycle number and process parameters. Depending on the type of metal or metal oxide used in the deposition, the catalytic applications of the resultant materials may show variations. While semiconducting metal oxides (e.g., $\mathrm{ZnO}$ and $\mathrm{TiO}_{2}$ ) were commonly exploited for photocatalytic applications, the deposition of high catalytic noble metal atoms, such as $\mathrm{Pd}, \mathrm{Pt}$, and $\mathrm{Ru}$, on electrospun fibers allows their use in nitroarene reduction and dehydrogenation reactions. Such metal deposited nanofibrous materials were also exploited for the electrochemical catalysis, including oxygen reduction/evolution reactions and water splitting. Since the catalytic metal atoms are chemically attached to the material surface, the resultant materials can be reused many times with similar catalytic activity with a further advantage of facile separation from the products. Overall, ALD is a unique and facile approach for the preparation of catalytic materials as mono or bimetallic nanoparticles and nanolayers on various electrospun materials, and therefore, they find more applications in catalysis in the coming years. The potential of this combination could be further enhanced by preparing hierarchical structures through hydrothermal and other techniques. The combination of electrospinning and ALD has been vastly explored in energy storage applications, where lithium, sodium, and sulfur-based batteries were studied. Alternative anode-materials, such as $\mathrm{MoS}_{2}$, Sn, etc. were studied with combinations of $\mathrm{SnO}_{2}, \mathrm{TiO}_{2}$, etc. The design of nanostructures is optimized such that the mechanical and structural integrity of the anode is retained accounting for volume changes during charge-discharge cycles, while not undermining the storage capacity of the battery. Also, the conventional electrodes based on carbon are also explored, and further improvements have been recorded through the deposition of metallic $\mathrm{Sn}, \mathrm{Ru}$ nanoparticles. Heterostructures of $\mathrm{ZnO}, \mathrm{SnO}_{2}, \mathrm{TiO}_{2}$, and $\mathrm{CuO}$ depicted unique surface functionalities and higher detection sensitivities toward ethanol vapor, $\mathrm{O}_{2}, \mathrm{NO}_{2}, \mathrm{CO}, \mathrm{NH}_{3}, \mathrm{H}_{2}$, and others. Indeed, this gas sensitivity hinders the faster response when the same materials are used as photodetectors by forming a depletion layer at the surface. Under illumination, $\mathrm{O}_{2}$ for instance desorbs from the surface which affects the photoluminescence of $\mathrm{ZnO}$. By monitoring the photoluminescence, one can probe the concentration of gas by comparing the emissions across the near band edge and that of the defect level. Last, but not least, an amazing potential of electrospinning and ALD is seen with reference to the photodetectors. In this application, the heterostructures (example, $\mathrm{BiVO}_{4}-\mathrm{ZnO}, \mathrm{SnO}_{2}-\mathrm{ZnO}$ ) with a built-in electric field (due to band alignment) separates the photogenerated charge carriers enhancing the response.

\section{AUTHOR INFORMATION}

\section{Corresponding Authors}

Sesha Vempati - Department of Physics, Indian Institute of Technology Bhilai, Raipur 492015, India; 이잉.org/00000002-0536-7827; Email: sesha@iitbhilai.ac.in

Tamer Uyar - Department of Fiber Science and Apparel Design, College of Human Ecology, Cornell University, Ithaca, New York 14850, United States; 이이이.org/0000-0002-39894481; Email: tu46@cornell.edu

\section{Authors}

Kugalur Shanmugam Ranjith - Department of Energy and Material Engineering, Dongguk University-Seoul, Seoul 04620, South Korea; 이이. orid.org/0000-0003-3942-8672

Fuat Topuz - Institute of Materials Science \& Nanotechnology, UNAM-National Nanotechnology Research Center, Bilkent University, Ankara 06800, Turkey

Necmi Biyikli - Electrical and Computer Engineering, University of Connecticut, Storrs, Connecticut 06269, United States

Complete contact information is available at:

https://pubs.acs.org/10.1021/acsanm.0c01120

\section{Notes}

The authors declare no competing financial interest.

\section{REFERENCES}

(1) Ashfold, M. N. R.; Claeyssens, F.; Fuge, G. M.; Henley, S. J. Pulsed Laser Ablation and Deposition of Thin Films. Chem. Soc. Rev. 2004, 33, 23-31.

(2) Crutchley, R. J. Chemical Vapor Deposition and Atomic Layer Deposition: Precursor Design and Application. Coord. Chem. Rev. 2013, 257, 3153-3384.

(3) Yan, Y.; Li, B.; Guo, W.; Pang, H.; Xue, H. Vanadium Based Materials as Electrode Materials for High Performance Supercapacitors. J. Power Sources 2016, 329, 148-169.

(4) Kayaci, F.; Vempati, S.; Ozgit-Akgun, C.; Biyikli, N.; Uyar, T. Enhanced Photocatalytic Activity of Homoassembled Zno Nanostructures on Electrospun Polymeric Nanofibers: A Combination of Atomic Layer Deposition and Hydrothermal. Appl. Catal., B 2014, 156-157, 173-183.

(5) Doshi, J.; Reneker, D. H. Electrospinning Process and Applications of Electrospun Fibers. J. Electrost. 1995, 35, 151-160.

(6) Ahvenniemi, E.; Akbashev, A. R.; Ali, S.; Bechelany, M.; Berdova, M.; Boyadjiev, S.; Cameron, D. C.; Chen, R.; Chubarov, M.; Cremers, V.; Devi, A.; Drozd, V.; Elnikova, L.; Gottardi, G.; Grigoras, K.; Hausmann, D. M.; Hwang, C. S.; Jen, S.-H.; Kallio, T.; Kanervo, J.; Khmelnitskiy, I.; Kim, D. H.; Klibanov, L.; Koshtyal, Y.; Krause, A. O. I.; Kuhs, J.; Karkkanen, I.; Kaariainen, M.-L.; Kaariainen, T.; Lamagna, L.; Łapicki, A. A.; Leskela, M.; Lipsanen, H.; Lyytinen, J.; Malkov, A.; Malygin, A.; Mennad, A.; Militzer, C.; Molarius, J.; Norek, M.łg.; Ozgit-Akgun, C.; Panov, M.; Pedersen, H.; Piallat, F.; Popov, G.; Puurunen, R. L.; Rampelberg, G.; Ras, R. H. A.; Rauwel, E.; Roozeboom, F.; Sajavaara, T.; Salami, H.; Savin, H.; Schneider, N.; Seidel, T. E.; Sundqvist, J.; Suyatin, D. B.; Torndahl, T.; van Ommen, J. R.; Wiemer, C.; Ylivaara, O. M. E.; Yurkevich, O. Review Article: Recommended Reading List of Early Publications on Atomic Layer Deposition-Outcome of the "Virtual Project on the History of Ald. J. Vac. Sci. Technol., A 2017, 35, 010801.

(7) Ritala, M.; Leskel€a, M. Atomic Layer Deposition in Handbook of Thin Film Materials; Nalwa, H. S., Ed.; Academic: San Diego, CA, 2002; Vol. 1, pp 103-159. 
(8) Puurunen, R. L. Surface Chemistry of Atomic Layer Deposition: A Case Study for the Trimethylaluminum/Water Process. J. Appl. Phys. 2005, 97, 121301.

(9) George, S. M. Atomic Layer Deposition: An Overview. Chem. Rev. 2010, 110, 111.

(10) Parsons, G. N.; Elam, J. W.; George, S. M.; Haukka, S.; Jeon, H.; Kessels, W. M. M.; Leskela, M.; Poodt, P.; Ritala, M.; Rossnagel, S. M. History of Atomic Layer Deposition and Its Relationship with the American Vacuum Society. J. Vac. Sci. Technol., A 2013, 31, 050818.

(11) Vempati, S.; Shetty, A.; Dawson, P.; Nanda, K.; Krupanidhi, S. Solution-Based Synthesis of Cobalt-Doped Zno Thin Films. Thin Solid Films 2012, 524, 137-143.

(12) Vempati, S.; Shetty, A.; Dawson, P.; Nanda, K.; Krupanidhi, S. Cobalt-Doped Zno Nanowires on Quartz: Synthesis by Simple Chemical Method and Characterization. J. Cryst. Growth 2012, 343, $7-12$.

(13) Taylor, G. I. Electrically Driven Jets. Proc. Roy Soc. Lond A 1969, 313, 453-475.

(14) Celebioglu, A.; Uyar, T. Cyclodextrin Nanofibers by Electrospinning. Chem. Commun. 2010, 46, 6903-6905.

(15) Mackus, A. J. M.; Bol, A. A.; Kessels, W. M. M. The Use of Atomic Layer Deposition in Advanced Nanopatterning. Nanoscale 2014, 6, 10941-10960.

(16) Zheng, Y. B.; Juluri, B. K.; Mao, X.; Walker, T. R.; Huang, T. J. Systematic Investigation of Localized Surface Plasmon Resonance of Long-Range Ordered Au Nanodisk Arrays. J. Appl. Phys. 2008, 103, 014308.

(17) Xie, M.; Sun, X.; Zhou, C.; Cavanagh, A. S.; Sun, H.; Hu, T.; Wang, G.; Lian, J.; George, S. M. Amorphous Ultrathin $\mathrm{TiO}_{2}$ Atomic Layer Deposition Films on Carbon Nanotubes as Anodes for Lithium Ion Batteries. J. Electrochem. Soc. 2015, 162, A974-A981.

(18) Jung, S.-K.; Gwon, H.; Hong, J.; Park, K.-Y.; Seo, D.-H.; Kim, H.; Hyun, J.; Yang, W.; Kang, K. Understanding the Degradation Mechanisms of $\mathrm{LiNi}_{0.5} \mathrm{Co}_{0.2} \mathrm{Mn}_{0.3} \mathrm{O}_{2}$ Cathode Material in Lithium Ion Batteries. Adv. Energy Mater. 2014, 4, 1300787.

(19) van-Delft, J. A.; Garcia-Alonso, D.; Kessels, W. M. M. Atomic Layer Deposition for Photovoltaics: Applications and Prospects for Solar Cell Manufacturing. Semicond. Sci. Technol. 2012, 27, 074002.

(20) Schmidt, J.; Merkle, A.; Brendel, R.; Hoex, B.; de Sanden, M. C. M. v.; Kessels, W. M. M. Surface Passivation of High-Efficiency Silicon Solar Cells by Atomic-Layer-Deposited $\mathrm{Al}_{2} \mathrm{O}_{3}$. Prog. Photovoltaics 2008, 16, 461 .

(21) Richter, A.; Benick, J.; Hermle, M.; Glunz, S. W. Excellent Silicon Surface Passivation with 5 A Thin Ald Al2o3 Layers: Influence of Different Thermal Post-Deposition Treatments. Phys. Status Solidi RRL 2011, 5, 202.

(22) O’Neill, B. J.; Jackson, D. H. K.; Lee, J.; Canlas, C.; Stair, P. C.; Marshall, C. L.; Elam, J. W.; Kuech, T. F.; Dumesic, J. A.; Huber, G. W. Catalyst Design with Atomic Layer Deposition. ACS Catal. 2015, 5, 1804-1825.

(23) Lu, J.; Elam, J. W.; Stair, P. C. Synthesis and Stabilization of Supported Metal Catalysts by Atomic Layer Deposition. Acc. Chem. Res. 2013, 46, 1806-1815.

(24) Khalily, M. A.; Eren, H.; Akbayrak, S.; Susapto, H. H.; Biyikli, N.; Ozkar, S.; Guler, M. O. Facile Synthesis of Three-Dimensional Pt$\mathrm{TiO}_{2}$ Nano-Networks: A Highly Active Catalyst for the Hydrolytic Dehydrogenation of Ammonia-Borane. Angew. Chem., Int. Ed. 2016, 55, 12257.

(25) Kim, B. J.; Kim, D. H.; Lee, Y.-Y.; Shin, H.-W.; Han, G. S.; Hong, J. S.; Mahmood, K.; Ahn, T. K.; Joo, Y.-C.; Hong, K. S.; Park, N.-G.; Lee, S.; Jung, H. S. Highly Efficient and Bending Durable Perovskite Solar Cells: Toward a Wearable Power Source. Energy Environ. Sci. 2015, 8, 916.

(26) Sheng, J.; Han, K.-L.; Hong, T. H.; Choi, W.-H.; Park, J.-S. Review of Recent Progresses on Flexible Oxide Semiconductor Thin Film Transistors Based on Atomic Layer Deposition Processes. J. Semicond. 2018, 39, 011008.
(27) Jung, J.-W.; Lee, C.-L.; Yu, S.; Kim, I.-D. Electrospun Nanofibers as a Platform for Advanced Secondary Batteries: A Comprehensive Review. J. Mater. Chem. A 2016, 4, 703-750.

(28) Thomas, M.; Rajiv, S. Dye-Sensitized Solar Cells Based on an Electrospun Polymer Nanocomposite Membrane as Electrolyte. New J. Chem. 2019, 43, 4444-4454.

(29) Pan, S.; Wang, Y.; Li, M.; Huang, G.; Mei, Y. Method for Preparing Photoanode of Dye-Sensitized Solar Cell. Chinese Patent CN102832051A, 2012.

(30) Qin, X.; Subianto, S. Electrospun Nanofibers for Filtration Applications; Woodhead Publishing Series in Textiles, 2017.

(31) Mirjalili, M.; Zohoori, S. Review for Application of Electrospinning and Electrospun Nanofibers Technology in Textile Industry. J. Nanostruct Chem. 2016, 6, 207-213.

(32) Uyar, T.; Kny, E. Electrospun Materials for Tissue Engineering and Biomedical Applications: Research, Design and Commercialization; Woodhead Publishing, 2017.

(33) Torres-Martinez, E. J.; Cornejo Bravo, J. M.; Serrano Medina, A.; Perez Gonzalez, G. L.; Villarreal Gomez, L. J. A Summary of Electrospun Nanofibers as Drug Delivery System: Drugs Loaded and Biopolymers Used as Matrices. Curr. Drug Delivery 2018, 15, 13601374.

(34) Thavasi, V.; Singh, G.; Ramakrishna, S. Electrospun Nanofibers in Energy and Environmental Applications. Energy Environ. Sci. 2008, $1,205-221$.

(35) Arslan, O.; Topuz, F.; Eren, H.; Biyikli, N.; Uyar, T. Pd Nanocube Decoration onto Flexible Nanofibrous Mats of Core-Shell Polymer-Zno Nanofibers for Visible Light Photocatalysis. New J. Chem. 2017, 41, 4145-4156.

(36) Li, J.; Chen, X.; Xu, W.; Nam, C.-Y.; Shi, Y. TiO 2 Nanofiber Solid-State Dye Sensitized Solar Cells with Thin Tio2 Hole Blocking Layer Prepared by Atomic Layer Deposition. Thin Solid Films 2013, 536, 275-279.

(37) Ryu, W.-H.; Jung, J.-W.; Park, K.; Kim, S.-J.; Kim, I.-D. VineLike $\mathrm{MoS}_{2}$ Anode Materials Self-Assembled from 1-D Nanofibers for High Capacity Sodium Rechargeable Batteries. Nanoscale 2014, 6, 10975-10981.

(38) Mao, M.; Yan, F.; Cui, C.; Ma, J.; Zhang, M.; Wang, T.; Wang, C. Pipe-Wire $\mathrm{TiO}_{2}$-Sn@Carbon Nanofibers Paper Anodes for Lithium and Sodium Ion Batteries. Nano Lett. 2017, 17, 3830-3836.

(39) Wang, X.; Fan, L.; Gong, D.; Zhu, J.; Zhang, Q.; Lu, B. CoreShell Ge@Graphene@TiO ${ }_{2}$ Nanofibers as a High-Capacity and Cycle-Stable Anode for Lithium and Sodium Ion Battery. Adv. Funct. Mater. 2016, 26, 1104-1111.

(40) Yang, J.; Mi, H.; Luo, S.; Li, Y.; Zhang, P.; Deng, L.; Sun, L.; Ren, X. Atomic Layer Deposition of Tio2 on Nitrogen-Doped Carbon Nanofibers Supported Ru Nanoparticles for Flexible Li-O2 Battery: A Combined Dft and Experimental Study. J. Power Sources 2017, 368, $88-96$.

(41) Zhu, Y.; Fan, X.; Suo, L.; Luo, C.; Gao, T.; Wang, C. Electrospun $\mathrm{FeS}_{2} @$ Carbon Fiber Electrode as a High Energy Density Cathode for Rechargeable Lithium Batteries. ACS Nano 2016, 10, 1529-1538.

(42) Shen, X.; Li, C.; Shi, C.; Yang, C.; Deng, L.; Zhang, W.; Peng, L.; Dai, J.; Wu, D.; Zhang, P.; Zhao, J. Core-Shell Structured Ceramic Nonwoven Separators by Atomic Layer Deposition for Safe LithiumIon Batteries. Appl. Surf. Sci. 2018, 441, 165-173.

(43) Ma, D.; Li, Y.; Yang, J.; Mi, H.; Luo, S.; Deng, L.; Yan, C.; Rauf, M.; Zhang, P.; Sun, X.; Ren, X.; Li, J.; Zhang, H. New Strategy for Polysulfide Protection Based on Atomic Layer Deposition of Tio2 onto Ferroelectric-Encapsulated Cathode: Toward Ultra Stable FreeStanding Room Temperature Sodium-Sulfur Batteries. Adv. Funct. Mater. 2018, 28, 1705537.

(44) Zhu, J.; Wang, T.; Fan, F.; Mei, L.; Lu, B. Atomic-Scale Control of Silicon Expansion Space as Ultrastable Battery Anodes. ACS Nano 2016, 10, 8243-8251.

(45) Kayaci, F.; Vempati, S.; Ozgit-Akgun, C.; Donmez, I.; Biyikli, N.; Uyar, T. Transformation of Polymer-Zno Core-Shell Nanofibers into Zno Hollow Nanofibers: Intrinsic Defect Reorganization in Zno 
and Its Influence on the Photocatalysis. Appl. Catal., B 2015, 176$177,646-653$.

(46) Kayaci, F.; Vempati, S.; Ozgit-Akgun, C.; Donmez, I.; Biyikli, N.; Uyar, T. Selective Isolation of the Electron or Hole in Photocatalysis: $\mathrm{ZnO}-\mathrm{TiO}_{2}$ and $\mathrm{TiO}_{2}-\mathrm{ZnO}$ Core-Shell Structured Heterojunction Nanofibers Via Electrospinning and Atomic Layer Deposition. Nanoscale 2014, 6, 5735-5745.

(47) Lopez de Dicastillo, C.; Patino, C.; Galotto, M. J.; Palma, J. L.; Alburquenque, D.; Escrig, J. Novel Antimicrobial Titanium Dioxide Nanotubes Obtained through a Combination of Atomic Layer Deposition and Electrospinning Technologies. Nanomaterials 2018, $8,128$.

(48) Weber, M.; Iatsunskyi, I.; Coy, E.; Miele, P.; Cornu, D.; Bechelany, M. Novel and Facile Route for the Synthesis of Tunable Boron Nitride Nanotubes Combining Atomic Layer Deposition and Annealing Processes for Water Purification. Adv. Mater. Interfaces 2018, 5, 1800056.

(49) Hao, W.; Marichy, C.; Brioude, A. Promising Properties of Ald Boron Nitride Nanotube Mats for Water Purification. Environ. Sci.: Nano 2017, 4, 2311-2320.

(50) Boyadjiev, S. I.; Keri, O.; Bardos, P.; Firkala, T.; Gaber, F.; Nagy, Z. K.; Baji, Z.; Takacs, M.; Szilagyi, I. M. Tio2/Zno and Zno/ Tio 2 Core/Shell Nanofibers Prepared by Electrospinning and Atomic Layer Deposition for Photocatalysis and Gas Sensing. Appl. Surf. Sci. 2017, 424, 190-197.

(51) Park, J. Y.; Choi, S.-W.; Lee, J.-W.; Lee, C.; Kim, S. S. Synthesis and Gas Sensing Properties of Tio2-Zno Core-Shell Nanofibers. J. Am. Ceram. Soc. 2009, 92, 2551-2554.

(52) Viter, R.; Iatsunskyi, I.; Fedorenko, V.; Tumenas, S.; Balevicius, Z.; Ramanavicius, A.; Balme, S.; Kempinski, M.; Nowaczyk, G.; Jurga, S.; Bechelany, M. Enhancement of Electronic and Optical Properties of Zno/Al2o3 Nanolaminate Coated Electrospun Nanofibers. J. Phys. Chem. C 2016, 120, 5124-5132.

(53) Hu, M.; Teng, F.; Chen, H.; Jiang, M.; Gu, Y.; Lu, H.; Hu, L.; Fang, X. Novel $\Omega$-Shaped Core-Shell Photodetector with High Ultraviolet Selectivity and Enhanced Responsivity. Adv. Funct. Mater. 2017, 27, 1704477.

(54) Ozgit-Akgun, C.; Kayaci, F.; Vempati, S.; Haider, A.; Celebioglu, A.; Goldenberg, E.; Kizir, S.; Uyar, T.; Biyikli, N. Fabrication of Flexible Polymer-Gan Core-Shell Nanofibers by the Combination of Electrospinning and Hollow Cathode PlasmaAssisted Atomic Layer Deposition. J. Mater. Chem. C 2015, 3, 5199-5206.

(55) Haider, A.; Ozgit-Akgun, C.; Kayaci, F.; Okyay, A. K.; Uyar, T.; Biyikli, N. Fabrication of Aln/Bn Bishell Hollow Nanofibers by Electrospinning and Atomic Layer Deposition. APL Mater. 2014, 2, 096109.

(56) Jeun, J.-H.; Park, K.-Y.; Kim, D.-H.; Kim, W.-S.; Kim, H.-C.; Lee, B.-S.; Kim, H.; Yu, W.-R.; Kang, K.; Hong, S.-H. Sno2@Tio2 Double-Shell Nanotubes for a Lithium Ion Battery Anode with Excellent High Rate Cyclability. Nanoscale 2013, 5, 8480-8483.

(57) Katoch, A.; Kim, J.-H.; Kim, S. S. Tio2/Zno Inner/Outer Double-Layer Hollow Fibers for Improved Detection of Reducing Gases. ACS Appl. Mater. Interfaces 2014, 6, 21494-21499.

(58) Donmez, I.; Kayaci, F.; Ozgit-Akgun, C.; Uyar, T.; Biyikli, N. Fabrication of Hafnia Hollow Nanofibers by Atomic Layer Deposition Using Electrospun Nanofiber Templates. J. Alloys Compd. 2013, 559, $146-151$.

(59) Ozgit-Akgun, C.; Kayaci, F.; Donmez, I.; Uyar, T.; Biyikli, N. Template-Based Synthesis of Aln Hollow Nanofibers Via PlasmaEnhanced Atomic Layer Deposition. In Nanotech Conference \& Expo 2012: An Interdisciplinary Integrative Forum on Nanotechnology, Microtechnology, Biotechnology and Cleantechnology, Santa Clara, CA, June 18-21, 2012, CRC Press, 2012; pp 675-678.

(60) Katoch, A.; Choi, S.-W.; Sub Kim, S. Effect of the Wall Thickness on the Gas-Sensing Properties of Zno Hollow Fibers. Nanotechnology 2014, 25, 455504.

(61) Park, J. Y.; Choi, S.-W.; Kim, S. S. A Synthesis and Sensing Application of Hollow Zno Nanofibers with Uniform Wall
Thicknesses Grown Using Polymer Templates. Nanotechnology 2010, 21, 475601.

(62) Heikkilae, P.; Hirvikorpi, T.; Hilden, H.; Sievaenen, J.; Hyvaerinen, L.; Harlin, A.; Vaehae-Nissi, M. High Surface Area Nanostructured Tubes Prepared by Dissolution of Ald-Coated Electrospun Fibers. J. Mater. Sci. 2012, 47, 3607-3612.

(63) Saquing, C. D.; Peng, Q.; Parsons, G. N.; Khan, S. A. Metal Nanoparticle-Loaded Al2O3Microtubes by Atomic Layer Deposition on Nanofiber Composite Templates. In 235th ACS Spring National Meeting, New Orleans, LA, April 6-10, 2008, American Chemical Society, 2008; pp PHYS-491.

(64) Choi, S.-W.; Park, J. Y.; Lee, C.; Lee, J. G.; Kim, S. S. Synthesis of Highly Crystalline Hollow Tio2 Fibers Using Atomic Layer Deposition on Polymer Templates. J. Am. Ceram. Soc. 2011, 94, 1974-1977.

(65) Kim, W.-S.; Lee, B.-S.; Kim, D.-H.; Kim, H.-C.; Yu, W.-R.; Hong, S.-H. Sno2 Nanotubes Fabricated Using Electrospinning and Atomic Layer Deposition and Their Gas Sensing Performance. Nanotechnology 2010, 21, 245605.

(66) Pereira, A.; Escrig, J.; Palma, J. L.; de Dicastillo, C. L.; Patino, C.; Galotto, M. J. Magnetic Nanotubes Obtained from Atomic Layer Deposition Coated Electrospun Nanofibers. J. Vac. Sci. Technol., B: Nanotechnol. Microelectron.: Mater., Process., Meas., Phenom. 2018, 36, 061803.

(67) Liang, Z.; Hou, H.; Song, K.; Zhang, K.; Fang, Z.; Gao, F.; Wang, L.; Chen, D.; Yang, W.; Zeng, H. Boosting the Photoelectrochemical Activities of All-Inorganic Perovskite Srtio3 Nanofibers by Engineering Homo/Hetero Junctions. J. Mater. Chem. A 2018, 6, 17530-17539.

(68) Celebioglu, A.; Ranjith, K. S.; Eren, H.; Biyikli, N.; Uyar, T. Surface Decoration of Pt Nanoparticles Via Ald with Tio2 Protective Layer on Polymeric Nanofibers as Flexible and Reusable Heterogeneous Nanocatalysts. Sci. Rep. 2017, 7, 13401.

(69) Di Mauro, A.; Fragala, M. E.; Privitera, V.; Impellizzeri, G. Zno for Application in Photocatalysis: From Thin Films to Nanostructures. Mater. Sci. Semicond. Process. 2017, 69, 44-51.

(70) Bechelany, M.; Drobek, M.; Vallicari, C.; Abou Chaaya, A.; Julbe, A.; Miele, P. Highly Crystalline Mof-Based Materials Grown on Electrospun Nanofibers. Nanoscale 2015, 7, 5794-5802.

(71) Sundaray, B.; Subramanian, V.; Natarajan, T. S.; Xiang, R.-Z.; Chang, C.-C.; Fann, W.-S. Electrospinning of Continuous Aligned Polymer Fibers. Appl. Phys. Lett. 2004, 84, 1222.

(72) Celebioglu, A.; Vempati, S.; Ozgit-Akgun, C.; Biyikli, N.; Uyar, T. Water-Soluble Non-Polymeric Electrospun Cyclodextrin Nanofiber Template for the Synthesis of Metal Oxide Tubes by Atomic Layer Deposition. RSC Adv. 2014, 4, 61698-61705.

(73) Pavan Kumar, V. S.; Jagadeesh Babu, V.; Raghuraman, G. K.; Dhamodharan, R.; Natarajan, T. S. Electrsopinning Can Be with Composites Not Just Pure Polymers. Giant Magnetoresistance of -Polymethylmethacrylate Nanocomposite Aligned Fibers Via Electrospinning. J. Appl. Phys. 2007, 101, 114317.

(74) Persano, L.; Camposeo, A.; Tekmen, C.; Pisignano, D. Industrial Upscaling of Electrospinning and Applications of Polymer Nanofibers: A Review. Macromol. Mater. Eng. 2013, 298, 504-520.

(75) Simons, H. L. Process and Apparatus for Producing Patterned Non-Woven Fabrics. U.S. Patent 3,280,229. 1966.

(76) How, T. V. Synthetic Vascular Grafts and Methods of Manufacturing Such Grafts, Us Patent Number No. US4552707, 1985.

(77) Berry, J. P. Method and Apparatus for Manufacturing Electrostatically Spun Structure. U.S. Patent 5,024,789, 1991.

(78) Kijeńska, E.; Swieszkowski, W. Electrospun Materials for Tissue Engineering and Biomedical Applications: Research, Design and Commercialization; Woodhead Publishing, 2017.

(79) Topuz, F.; Abdulhamid, M. A.; Nunes, S. P.; Szekely, G. Hierarchically Porous Electrospun Nanofibrous Mats Produced from Intrinsically Microporous Fluorinated Polyimide for the Removal of Oils and Non-Polar Solvents. Environ. Sci.: Nano 2020, DOI: $10.1039 /$ D0EN00084A. 
(80) Topuz, F.; Uyar, T. Antioxidant, Antibacterial and Antifungal Electrospun Nanofibers for Food Packaging Applications. Food Res. Int. 2020, 130, 108927.

(81) Vempati, S.; Natarajan, T. Flexible Polymer Microtubes and Microchannels Via Electrospinning. Mater. Lett. 2011, 65, 34933495.

(82) Patil, B.; Satilmis, B.; Khalily, M. A.; Uyar, T. ALD of NiOOH/ $\mathrm{Ni}(\mathrm{OH}) 2$ on Pim-1 Based Free-Standing Flexible Binder-Free Electrospun N-Doped Carbon Nanofibers: Nanocatalyst for Electrochemical Water Splitting in Alkaline Medium. ChemSusChem 2019, $12,1469-1477$.

(83) Srivastava, Y.; Marquez, M.; Thorsen, T. Microfluidic Electrospinning of Biphasic Nanofibers with Janus Morphology. Biomicrofluidics 2009, 3, 012801.

(84) Budd, P. M.; Ghanem, B. S.; Makhseed, S.; McKeown, N. B.; Msayib, K. J.; Tattershall, C. E. Polymers of Intrinsic Microporosity (Pims): Robust, Solution-Processable, Organic Nanoporous Materials. Chem. Commun. 2004, 4, 230-231.

(85) https://www.inovenso.com.

(86) http://bioinicia.com/.

(87) http://www.yflow.com/.

(88) http://www.electrospinning.co.uk.

(89) http://www.imetechnologies.com.

(90) https://www.spraybase.com/.

(91) http://www.linaribiomedical.com/index.php/electrospinning.

(92) https://www.elmarco.com/.

(93) https://www.4spin.info/.

(94) https://spingenix.com/.

(95) http://www.espintechnologies.com/.

(96) http://www.nanofibersolutions.com.

(97) www.holmarc.com.

(98) https://www.electro-spinning.com/.

(99) https://www.mecc-nano.com/.

(100) http://www.sncfibers.com/.

(101) http://revolutionfibres.com/.

(102) https://www.electro-spinning.com/electrospinning-spinneret. html.

(103) Balogh, A.; Farkas, B.; Verreck, G.; Mensch, J.; Borbás, E.; Nagy, B.; Marosi, G.; Nagy, Z. K. Ac and Dc Electrospinning of Hydroxypropylmethylcellulose with Polyethylene Oxides as Secondary Polymer for Improved Drug Dissolution. Int. J. Pharm. 2016, 505, 159-166.

(104) Knoops, H. C. M.; Faraz, T.; Arts, K.; Kessels, W. M. M. Status and Prospects of Plasma-Assisted Atomic Layer Deposition. J. Vac. Sci. Technol., A 2019, 37, 030902.

(105) Mohammad, A.; Shukla, D.; Ilhom, S.; Willis, B.; Johs, B.; Okyay, A. K.; Biyikli, N. Real-Time in Situ Ellipsometric Monitoring of Aluminum Nitride Film Growth Via Hollow-Cathode PlasmaAssisted Atomic Layer Deposition. J. Vac. Sci. Technol., A 2019, 37, 020927.

(106) Ozgit-Akgun, C.; Kayaci, F.; Donmez, I.; Uyar, T.; Biyikli, N. Template-Based Synthesis of Aluminum Nitride Hollow Nanofibers Via Plasma-Enhanced Atomic Layer Deposition. J. Am. Ceram. Soc. 2013, 96, 916.

(107) Vempati, S.; Kayaci-Senirmak, F.; Ozgit-Akgun, C.; Biyikli, N.; Uyar, T. Amorphous to Tetragonal Zirconia Nanostructures and Evolution of Valence and Core Regions. J. Phys. Chem. C 2015, 119, $23268-23273$.

(108) Nasr, M.; Viter, R.; Eid, C.; Warmont, F.; Habchi, R.; Miele, P.; Bechelany, M. Synthesis of Novel Zno/Znal2o4Multi Co-Centric Nanotubes and Their Long-Term Stability in Photocatalytic Application. RSC Adv. 2016, 6, 103692-103699.

(109) Kayaci, F.; Ozgit-Akgun, C.; Biyikli, N.; Uyar, T. SurfaceDecorated Zno Nanoparticles and Zno Nanocoating on Electrospun Polymeric Nanofibers by Atomic Layer Deposition for Flexible Photocatalytic Nanofibrous Membranes. RSC Adv. 2013, 3, 68176820.

(110) Hou, H.; Liu, H.; Gao, F.; Shang, M.; Wang, L.; Xu, L.; Wong, W.-Y.; Yang, W. Packaging Bivo4 Nanoparticles in Zno Microbelts for
Efficient Photoelectrochemical Hydrogen Production. Electrochim. Acta 2018, 283, 497-508.

(111) Lee, B.-S.; Kim, W.-S.; Kim, D.-H.; Kim, H.-C.; Hong, S.-H.; Yu, W.-R. Fabrication of Sno2 Nanotube Microyarn and Its Gas Sensing Behavior. Smart Mater. Struct. 2011, 20, 105019.

(112) Katoch, A.; Choi, S.-W.; Sun, G.-J.; Kim, H. W.; Kim, S. S. Mechanism and Prominent Enhancement of Sensing Ability to Reducing Gases in P/N Core-Shell Nanofiber. Nanotechnology 2014, 25,175501 .

(113) Szilágyi, I. M.; Santala, E.; Heikkilä, M.; Pore, V.; Kemell, M.; Nikitin, T.; Teucher, G.; Firkala, T.; Khriachtchev, L.; Räsänen, M.; Ritala, M.; Leskelä, M. Photocatalytic Properties of $\mathrm{WO}_{3} / \mathrm{TiO}_{2}$ Core/ Shell Nanofibers Prepared by Electrospinning and Atomic Layer Deposition. Chem. Vap. Deposition 2013, 19, 149-155.

(114) Jean, J.-H.; Kwak, H.; Kim, W.-S.; Kim, H.-C.; Park, K.-Y.; Kim, H.; Yang, H.-S.; Yu, W.-R.; Kang, K.; Hong, S.-H. Tio2@Sno2@ Tio2 Triple-Shell Nanotube Anode for High-Performance LithiumIon Batteries. J. Solid State Electrochem. 2017, 21, 2365-2371.

(115) Mills, A.; Le Hunte, S. An Overview of Semiconductor Photocatalysis. J. Photochem. Photobiol., A 1997, 108, 1-35.

(116) Fox, M. A.; Dulay, M. T. Heterogeneous Photocatalysis. Chem. Rev. 1993, 93, 341-357.

(117) Lang, X.; Chen, X.; Zhao, J. Heterogeneous Visible Light Photocatalysis for Selective Organic Transformations. Chem. Soc. Rev. 2014, 43, 473-486.

(118) Khalily, M. A.; Yurderi, M.; Haider, A.; Bulut, A.; Patil, B.; Zahmakiran, M.; Uyar, T. Atomic Layer Deposition of Ruthenium Nanoparticles on Electrospun Carbon Nanofibers: A Highly Efficient Nanocatalyst for the Hydrolytic Dehydrogenation of Methylamine Borane. ACS Appl. Mater. Interfaces 2018, 10, 26162-26169.

(119) Kayaci, F.; Ozgit-Akgun, C.; Donmez, I.; Biyikli, N.; Uyar, T. Polymer-Inorganic Core-Shell Nanofibers by Electrospinning and Atomic Layer Deposition: Flexible Nylon-Zno Core-Shell Nanofiber Mats and Their Photocatalytic Activity. ACS Appl. Mater. Interfaces 2012, 4, 6185-6194.

(120) Di Mauro, A.; Fragalà, M. E.; Privitera, V.; Impellizzeri, G. Zno for Application in Photocatalysis: From Thin Films to Nanostructures. Mater. Sci. Semicond. Process. 2017, 69, 44-51.

(121) Nasr, M.; Viter, R.; Eid, C.; Habchi, R.; Miele, P.; Bechelany, M. Optical and Structural Properties of Al2o3 Doped Zno Nanotubes Prepared by Ald and Their Photocatalytic Application. Surf. Coat. Technol. 2018, 343, 24-29.

(122) Dai, H.-Q.; Xu, H.; Zhou, Y.-N.; Lu, F.; Fu, Z.-W. Electrochemical Characteristics of $\mathrm{Al}_{2} \mathrm{O}_{3}$-Doped $\mathrm{Zno}$ Films by Magnetron Sputtering. J. Phys. Chem. C 2012, 116, 1519-1525.

(123) Santala, E.; Kemell, M.; Leskela, M.; Ritala, M. The Preparation of Reusable Magnetic and Photocatalytic Composite Nanofibers by Electrospinning and Atomic Layer Deposition. Nanotechnology 2009, 20, 035602.

(124) Celebioglu, A.; Ranjith, K. S.; Eren, H.; Biyikli, N.; Uyar, T. Surface Decoration of Pt Nanoparticles Via Ald with Tio2 Protective Layer on Polymeric Nanofibers as Flexible and Reusable Heterogeneous Nanocatalysts. Sci. Rep. 2017, 7, 13401.

(125) Topuz, F.; Uyar, T. Atomic Layer Deposition of Palladium Nanoparticles on a Functional Electrospun Poly-Cyclodextrin Nanoweb as a Flexible and Reusable Heterogeneous Nanocatalyst for the Reduction of Nitroaromatic Compounds. Nanoscale Adv. 2019, 1, 4082-4089.

(126) Dwyer, D. B.; Lee, D. T.; Boyer, S.; Bernier, W. E.; Parsons, G. N.; Jones, W. E. Toxic Organophosphate Hydrolysis Using NanofiberTemplated Uio-66-Nh2Metal-Organic Framework Polycrystalline Cylinders. ACS Appl. Mater. Interfaces 2018, 10, 25794-25803.

(127) Arslan, O.; Eren, H.; Biyikli, N.; Uyar, T. Reusable and Flexible Heterogeneous Catalyst for Reduction of Tnt by Pd Nanocube Decorated Zno Nanolayers onto Electrospun Polymeric Nanofibers. ChemistrySelect 2017, 2, 8790-8798.

(128) Veluru, J. B.; Manippady, K. K.; Rajendiren, M.; Mya Mya, K.; Rayavarapu, P. R.; Appukuttan, S. N.; Seeram, R. Photocatalytic 
Hydrogen Generation by Splitting of Water from Electrospun Hybrid Nanostructures. Int. J. Hydrogen Energy 2013, 38, 4324-4333.

(129) Babu, V. J.; Kumar, M. K.; Nair, A. S.; Kheng, T. L.; Allakhverdiev, S. I.; Ramakrishna, S. Visible Light Photocatalytic Water Splitting for Hydrogen Production from N-Tio2 Rice Grain Shaped Electrospun Nanostructures. Int. J. Hydrogen Energy 2012, 37, 8897-8904.

(130) Du, Q.; Wu, J.; Yang, H. Pt@Nb-Tio2 Catalyst Membranes Fabricated by Electrospinning and Atomic Layer Deposition. ACS Catal. 2014, 4, 144-151.

(131) Khalily, M. A.; Patil, B.; Yilmaz, E.; Uyar, T. Atomic Layer Deposition of Co3o4 Nanocrystals on N-Doped Electrospun Carbon Nanofibers for Oxygen Reduction and Oxygen Evolution Reactions. Nanoscale Advances 2019, 1, 1224-1231.

(132) Barhoum, A.; El-Maghrabi, H. H.; Iatsunskyi, I.; Coy, E.; Renard, A.; Salameh, C.; Weber, M.; Sayegh, S.; Nada, A. A.; Roualdes, S.; Bechelany, M. Atomic Layer Deposition of Pd Nanoparticles on Self-Supported Carbon-Ni/Nio-Pd Nanofiber Electrodes for Electrochemical Hydrogen and Oxygen Evolution Reactions. J. Colloid Interface Sci. 2020, 569, 286-297.

(133) Schlicht, S.; Assaud, L.; Hansen, M.; Licklederer, M.; Bechelany, M.; Perner, M.; Bachmann, J. An Electrochemically Functional Layer of Hydrogenase Extract on an Electrode of Large and Tunable Specific Surface Area. J. Mater. Chem. A 2016, 4, 64876494.

(134) Du, Q.; Wu, J.; Yang, H. Pt@Nb-Tio2 Catalyst Membranes Fabricated by Electrospinning and Atomic Layer Deposition. ACS Catal. 2014, 4, 144-151.

(135) Li, Y.; Sun, Y.; Xu, G.; Lu, Y.; Zhang, S.; Xue, L.; Jur, J. S.; Zhang, X. Tuning Electrochemical Performance of Si-Based Anodes for Lithium-Ion Batteries by Employing Atomic Layer Deposition Alumina Coating. J. Mater. Chem. A 2014, 2, 11417-11425.

(136) Wee, G.; Soh, H. Z.; Cheah, Y. L.; Mhaisalkar, S. G.; Srinivasan, M. Synthesis and Electrochemical Properties of Electrospun V2o5 Nanofibers as Supercapacitor Electrodes. J. Mater. Chem. 2010, 20, 6720-6725.

(137) Kim, B.-H.; Kim, C. H.; Yang, K. S.; Rahy, A.; Yang, D. J. Electrospun Vanadium Pentoxide/Carbon Nanofiber Composites for Supercapacitor Electrodes. Electrochim. Acta 2012, 83, 335-340.

(138) Cho, S.; Kim, D.-H.; Lee, B.-S.; Jung, J.; Yu, W.-R.; Hong, S.H.; Lee, S. Ethanol Sensors Based on Zno Nanotubes with Controllable Wall Thickness Via Atomic Layer Deposition, an O2 Plasma Process and an Annealing Process. Sens. Actuators, B 2012, $162,300-306$.

(139) Katoch, A.; Abideen, Z. U.; Kim, J.-H.; Kim, S. S. Influence of Hollowness Variation on the Gas-Sensing Properties of Zno Hollow Nanofibers. Sens. Actuators, B 2016, 232, 698-704.

(140) Choi, S.-W.; Park, J. Y.; Kim, S. S. Synthesis of Sno2-Zno Core-Shell Nanofibers Via a Novel Two-Step Process and Their Gas Sensing Properties. Nanotechnology 2009, 20, 465603.

(141) Park, J. Y.; Choi, S.-W.; Kim, S. S. A Model for the Enhancement of Gas Sensing Properties in Sno2-Zno Core-Shell Nanofibres. J. Phys. D: Appl. Phys. 2011, 44, 205403.

(142) Katoch, A.; Choi, S.-W.; Sun, G.-J.; Kim, S. S. An Approach to Detecting a Reducing Gas by Radial Modulation of Electron-Depleted Shells in Core-Shell Nanofibers. J. Mater. Chem. A 2013, 1, 1358813596.

(143) Viter, R.; Chaaya, A. A.; Iatsunskyi, I.; Nowaczyk, G.; Kovalevskis, K.; Erts, D.; Miele, P.; Smyntyna, V.; Bechelany, M. Tuning of Zno 1d Nanostructures by Atomic Layer Deposition and Electrospinning for Optical Gas Sensor Applications. Nanotechnology 2015, 26, 105501.

(144) Chaaya, A. A.; Bechelany, M.; Balme, S.; Miele, P. Zno 1d Nanostructures Designed by Combining Atomic Layer Deposition and Electrospinning for Uv Sensor Applications. J. Mater. Chem. A 2014, 2, 20650-20658.

(145) Vempati, S.; Ozcan, S.; Uyar, T. Temporary and Permanent Changes to the Defect Equilibrium Due to Ultraviolet Exposure:
Surface and Bulk Effects on Zno Nanostructures. Appl. Surf. Sci. 2018, 457, 676-683.

(146) Vempati, S.; Ozcan, S.; Uyar, T. Temporary and Permanent Changes to the Defect Equilibrium Due to Ultraviolet Exposure: Surface and Bulk Effects on $\mathrm{ZnO}$ Nanostructures. Appl. Surf. Sci. 2018, 457, 676-683. 